Wang, J., Afshan, S. \& Gardner, L. (2017) Axial behaviour of prestressed high strength steel tubular members. Journal of Constructional Steel Research; 133: $547-563$.

\title{
Axial behaviour of prestressed high strength steel tubular members
}

\author{
J. Wang ${ }^{\mathrm{a}}$, S. Afshan ${ }^{\mathrm{b}, *}$, L. Gardner ${ }^{\mathrm{a}}$ \\ ${ }^{a}$ Imperial College London, London, UK \\ ${ }^{b}$ Brunel University London, London, $U K$
}

\begin{abstract}
The axial behaviour and design of hot-finished high strength steel tubular elements with internal prestressing cables, representing the chord members in prestressed trusses, are examined in this paper. A comprehensive programme of experiments and numerical modelling was performed, the results of which were combined to develop resistance expressions for the design of prestressed high strength steel members. A total of 12 tensile and 10 compressive member tests were carried out, with the key variables examined being the steel grade (S460 and S690), the initial prestress level and the presence of grout. Numerical models were developed to replicate the structural response of the compressive member tests and subsequently used to generate parametric results, where the member slenderness, size of prestressing cable, applied prestress level, steel grade (S460 or S690), and grout condition (grouted and non-grouted), were varied. The presence of cables was shown to enhance the tensile capacity of the members, while the addition of prestress resulted in extended elastic range. In compression, the effect of prestress was detrimental, and a modified Perry-Robertson method, developed in [1], was extended to hot-finished high strength steel members.
\end{abstract}

Keywords: High strength steels; Prestress; SHS; Hollow sections; Tension; Compression; Cable-in-tube system; Grout.

\section{Introduction}

Long-span steel trusses are commonly used in a broad range of modern structures, where there are demands for large column free spaces, such as in airport terminals, aircraft hangers, sports stadia and auditoriums. The overall economy of these long-span structures is governed by both their structural form as well as the materials chosen for their individual components. High strength steels (HSS), with yield strengths in excess of $460 \mathrm{~N} / \mathrm{mm}^{2}$, offer the potential for light-weight design and savings in the cost of material. However, while the higher strength of the material enables smaller cross-sections to be used, thereby reducing the structural self-weight, the stiffness (controlled by the Young's modulus of the material), which governs the serviceability limit state design, remains unchanged. Prestressed

\footnotetext{
${ }^{*}$ Corresponding author

Email address: Sheida.Afshan@brunel.ac.uk (S. Afshan)
} 
steel trusses, consisting of cable-in-tube systems, whereby the steel cables are housed within hollow structural sections, have been used in previous engineering applications [2] as a method for increasing load-bearing capacity and controlling deflections. Cables and prestressing enable the self-weight of the structure to be reduced and dead load deflections can be counter-acted by suitable profiling of the cable and adjustment of the prestress level; under live load, the elastic range of the structural response can be extended by prestressing, although the initial stiffness remains essentially unchanged. Combining the beneficial aspects of high strength steel and prestressing, prestressed HSS trusses can offer efficient solutions for long-span structures. An investigation into the structural behaviour and design of HSS prestressed cable-in-tube arched trusses has been carried out; the focus of the present paper is on the axial behaviour of HSS tubular elements with internal prestressing cables, representing the chord members in such trusses, while the wider research programme has included full scale tests and numerical modelling of prestressed arched trusses, which are reported in [3].

Previous studies of prestressed steel trusses have identified the enhanced structural performance brought about by the addition of prestressing cables and demonstrated the further improvements achieved through application of increased prestress levels. The influence of employing different prestressing cable profiles in Warren trusses was studied in [4], where it was shown that member forces and deflections decrease linearly with an increase in eccentricity of the cables. Studies investigating the use of different truss shapes and geometries, including straight truss girders [4-8], arched trusses [9-15] and space trusses $[16,17]$ have also been carried out. The behaviour and design of prestressed steel beams [18-24], columns [25-29] and individual cable-in-tube truss elements [1,30] have also been examined, where the potential benefits of prestressing at the structural member level were highlighted. In their recent study, Gosaye et al. [1,30] carried out an investigation into the tensile and compressive axial behaviour of ordinary strength steel tubular truss elements containing prestressing cables through a combination of analytical modelling, experiments and numerical modelling. The benefits of prestressing, in terms of increased member capacity and an extended elastic range, was demonstrated for the case of prestressed members subjected to axial tensile loading [30], while for prestressed members loaded in compression, the detrimental effects of prestressing were assessed and described through the development of a modified Perry-Robertson design method. With previous work on prestressed steel trusses focused mainly on tubular elements of ordinary strength steels, the objective of the present study is to extend the application of prestressing to high strength steels, thereby enabling the exploitation of the combined benefits of high strength steels and prestressing.

In the investigated structural system, the prestressed cables, housed within the bottom chord of tubular arched trusses, apply a compressive force to the chord members, which depending on the nature of the externally applied loads are subsequently subjected to either tensile (e.g. in the case of downward gravity loading) or compressive loading (e.g. in the case of wind uplift loading). The behaviour and design of 
prestressed chord elements subjected to both external tensile and compressive loading is the subject of this study, and includes a programme of laboratory testing and numerical modelling. Descriptions of the experimental investigation and the numerical modelling study, including the key results obtained and discussions thereof, leading to the establishment of design rules, are presented herein.

\section{Experimental investigation}

\subsection{Overview}

An experimental study was carried out in the Structures Laboratory at Imperial College London to assess the structural response of prestressed high strength steel cable-in-tube systems under tensile and compressive loading. In total 12 tensile (6 grouted and 6 non-grouted) and 10 compressive (6 grouted and 4 non-grouted) cable-in-tube member tests were conducted with a view to 1) assess the influence of prestress level and presence of grout on the response and 2) provide the necessary information to develop and validate numerical models. The tests carried out to characterise the material properties of the high strength steel tubes and grout are firstly described, followed by a description of the prestressing and grouting operations and an account of the tensile and compressive member tests. The high strength steel tubes were hot-finished grades S460 and S690 SHS $50 \times 50 \times 5$, which encased 7 wire strand Y1860S7 prestressing steel cables. Figure 1 depicts a typical test specimen, with the main components labelled.

The key variables of the cable-in-tube specimens were the steel grade ( $\mathrm{S} 460$ and S690), the presence of cable and initial prestress level (No cable, $\mathrm{P}_{\text {nom }}, 0.5 \mathrm{P}_{\text {opt }}$ and $\mathrm{P}_{\text {opt }}$ ) and the presence of grout, as shown in Table 1, where a list of the tested specimens is provided. Figure 2 shows the labelling system employed throughout the paper. The prestress level $\mathrm{P}_{\text {nom }}$ is a nominal prestress level of $5 \mathrm{kN}$ to ensure that the cables were taut during grouting and testing. The prestress level $\mathrm{P}_{\text {opt }}$, as defined in [30], is the optimum prestress force that causes the cable and the tube to yield simultaneously when the system is under tension, which maximises the extent of the elastic range. The unfactored value of $\mathrm{P}_{\text {opt }}$ depends on the material and geometric properties of the tube and cable, and can be calculated from Equation (1) [30], where A, E and $f_{y}$ are the cross-sectional area, Young's modulus and yield stress, respectively, of the cable (denoted with a subscript $\mathrm{c}$ ) and the tube (denoted with a subscript $\mathrm{t}$ ). From the measured properties reported in Table 2, it was determined that $\mathrm{P}_{\text {opt }}=189 \mathrm{kN}$ for the $\mathrm{S} 460$ members and $167 \mathrm{kN}$ for the $\mathrm{S} 690$ members. Note that the actual levels of prestress achieved in the experiments differed slightly from these target values and are reported in the following sections.

$$
P_{\text {opt }}=\frac{A_{t} A_{c}}{A_{t} E_{t}+A_{c} E_{c}}\left(f_{c y} E_{t}-f_{t y} E_{c}\right)
$$




\subsection{Material tests}

Material tests on the individual components of the cable-in-tube specimens, namely the steel tube, cable and grout, were first carried out, details of which are described in this section. The resulting material properties were used in the subsequent analysis of the member test results and in the development of numerical models of the tested specimens.

\subsubsection{Tube}

Tensile coupon tests on material extracted from the flat faces and corner regions of the SHS $50 \times 50 \times 5$ S460 and S690 high strength steel tubes used to fabricate the specimens were conducted to determine their basic engineering stress-strain response. Detailed descriptions of the tests, carried out following the procedures set out in EN ISO 6892-1 [31], are reported in [32], while a summary of the test results is given herein in Table 2. The material parameters reported in Table 2 are the Young's modulus $E_{t}$ and yield stress $f_{\text {ty }}$ of the flat faces of the tubes, which were similar to those of the corner regions. The cross-sectional areas of the S460 and S690 SHS $50 \times 50 \times 5$ steel tubes, $A_{t}$, used for determining the optimum prestress loads $\mathrm{P}_{\text {opt }}$ are also reported in Table 2. The measured stress-strain responses of the S460 and S690 materials are provided in Figure 3, where it is shown that both materials display a linear elastic response up to the yield point, followed by a yield plateau and strain hardening.

\subsubsection{Cable}

The nonlinear stress-strain response of the 7 wire strand Y1860S7 prestressing steel cables was determined from tensile tests on $2 \mathrm{~m}$ long specimens. The cable ends were passed through a chuck-wedge system, similar to that adopted for the member tests as explained in Section 2.3, at both ends which were in turn fitted into the jaws of the tensile test machine. The tests were performed in an Instron $2000 \mathrm{kN}$ hydraulic testing rig, under displacement control, at a constant rate of $0.5 \mathrm{~mm} / \mathrm{min}$. A Linear variable differential transformer (LVDT) was employed to measure the cable elongation, from which the axial strain in the cable was determined. The applied load was directly read from the tensile test machine and was used to calculate the axial stress in the cable. The cross-sectional area of the cable $A_{c}$ was taken as the sum of the cross-sectional areas of its individual seven strands obtained by measuring their diameters, and is reported in Table 2. A total of three tests were performed and the average measured Young's modulus $\mathrm{E}_{\mathrm{c}}$ and yield stress $\mathrm{f}_{\mathrm{cy}}$ (taken as the $0.2 \%$ proof stress due to the rounded nature of the stress-strain curve) of the cable are reported in Table 2.

\subsubsection{Grout}

Ten of the tested specimens were grouted, allowing the effect of the presence of grout on the axial behaviour of the cable-in-tube members to be examined. A Portland cement-based grout with a water-to-cement ratio of 0.35 was used. Standard cube tests were performed prior to the member tests to measure the grout 
strength. The grout mix was poured into $100 \mathrm{~mm}$ cube moulds and dried for one day, following which the samples were removed from the moulds and cured in water at room temperature. The cubes were tested 3 , 7, 14 and 28 days after casting using an Automax 5 testing machine under load control and at a constant rate of $0.3 \mathrm{~N} / \mathrm{mm}^{2} / \mathrm{s}$. Three cube samples were tested on each day and the average measured grout cube strength $f_{\text {gu }}$ is reported in Table 3. The cable-in-tube systems were tested 10 days after prestressing and grouting, when the grout strength was found to be approximately $50 \mathrm{~N} / \mathrm{mm}^{2}$. Additional cube tests were also performed on the same day as the member tests, the results of which are reported in Section 2.3.

\subsection{Preparation of specimens}

\subsubsection{Prestressing}

The SHS $50 \times 50 \times 5$ high strength steel tubes were cut to the required length, $2 \mathrm{~m}$ for the tensile specimens and $1 \mathrm{~m}$ for the compressive specimens, which were then welded onto $20 \mathrm{~mm}$ thick end plates with stiffeners added as shown in Figure 1. For the specimens prestressed to $0.5 \mathrm{P}_{\text {opt }}$ and $\mathrm{P}_{\text {opt }}$ levels, buckling of the steel tube during prestressing was prevented by using circular connecting collars fitted to the cables at suitable intervals, thereby reducing the tube effective length. The circular collars were dimensioned to an outer diameter matching the internal opening of the tube, and had a central hole to accommodate the prestressing cable. Cables with connecting collars attached at L/2 were inserted into the $1 \mathrm{~m}$ length specimens while connecting collars at L/4, L/2 and 3L/4 were employed in the $2 \mathrm{~m}$ length specimens. This reduced the buckling length of all specimens to $500 \mathrm{~mm}$. An Enerpac PTJ-6S pneumatic stressing jack was used to prestress the cable-in-tube specimens. The stress in the cables was held by an anchoring system, which consisted of a chuck and three wedges, as displayed in Figure 4. For the grouted specimens, a grouting collar was employed between the chuck and the end-plate to allow the grout to be poured into the specimens. During prestressing, the load was monitored by the strain gauges affixed to the mid-length of the specimens. The strain readings were translated into force by means of the tube Young's modulus and cross-sectional area. The achieved prestress loads for each specimen are reported Section 2.4.

\subsubsection{Grouting}

Grouting of the cable-in-tube specimens was carried out after prestressing. The specimens were set upright and the grout was poured into the tubes through the grouting collar using a funnel. Immediately after the grout was poured, the tubes were placed on a shaking table and a metal rod was used to tap the specimens along the length to ensure that the grout filled the tube completely. Vent holes were located at the ends of the specimens. For every grout mix, a series of cubes were also prepared and used to perform cube strength tests to obtain the strength-age evolution of the grout. Table 4 reports the measured grout cube strength for each of the tested specimens on days 1, 3, 7, 14 and 28 after grouting, as well as on the member test day. 


\subsection{Experimental set-up and instrumentation}

\subsubsection{Tensile member tests}

A total of 12 cable-in-tube specimens were tested under axial tensile loading. Accurate measurements of the geometric dimensions of the test specimens were made prior to testing and are reported in Table 5, where $L_{0}$ is the specimen length prior to prestressing, $b$ is the section width, $h$ is the section depth, $t$ is the section thickness and $\mathrm{r}_{\mathrm{ex}}$ is the average external corner radius, as shown in Figure 5. The actual measured initial prestress force $P_{i}$ is also reported in Table 5 for each of the tested cable-in-tube specimens. All tests were performed in an Instron $2000 \mathrm{kN}$ hydraulic testing machine, where displacement control at a constant rate of $0.5 \mathrm{~mm} / \mathrm{min}$ was used to drive the testing machine. The end-platens of the specimens were bolted onto the base and the moving head of the testing machine, as illustrated in Figures 6a and 6b for the non-grouted and grouted specimens, respectively. The applied load, axial extension and longitudinal strain at the mid-height of the tubes were recorded during the tests at $1 \mathrm{~s}$ intervals, where the axial load and displacement were read from the loading machine directly, and the tube strains were obtained from four strain gauges fixed to the four faces of the tube at mid-length (Figure 5). In the non-grouted member tests, the employment of a load-cell, as presented in Figure 6a, also allowed the cable force to be monitored, whereas for the grouted specimens, the load cell could not be used due to the presence of the grouting collar.

\subsubsection{Compressive member tests}

To investigate the compressive response of the high strength steel cable-in-tube systems, a total of 10 specimens were tested. The measured geometric dimensions of the compressive test specimens, as well as the actual level of applied prestress $P_{i}$, are reported in Table 6 . All tests were performed in an Instron $2000 \mathrm{kN}$ hydraulic testing machine, with the test set-up shown in Figure 7. Pin-ended boundary conditions were applied through hardened steel knife edge supports, which allowed only in-plane rotation of the members about one axis. Cylinders were used to connect the knife edges to the end-plates, encasing the anchoring system at both ends. The buckling length of the specimens, $\mathrm{L}_{\mathrm{cr}}$, was taken as the distance between the top and bottom knife edges, and is equal to $\mathrm{L}_{0}-\mathrm{P}_{\mathrm{i}} / \mathrm{E}_{\mathrm{t}} \mathrm{A}_{\mathrm{t}}+175 \times 2$, where the 175 (in $\mathrm{mm}$ ) distance is as illustrated in Figure 7a. Strain gauges attached to the four faces of the tubes at mid-height were employed to measure the strain, and a string potentiometer was used to measure the lateral deflection at mid-height during the tests. The applied load was read directly from the loading machine. All variables were recorded at $1 \mathrm{~s}$ interval. The measured initial eccentricity, comprising the initial end loading eccentricity $e_{i}$ plus initial global geometric imperfection amplitude $\omega_{i}$, of each of the tested compressive members was derived from the strain gauge readings, as explained below; the mesured values of $\left(\omega_{i}+e_{i}\right)$ are reported in Table 6 .

The strain gauge readings were used to obtain the actual initial eccentricity of each of the tested members. For the non-grouted specimens, the relationship between the moment $\mathrm{M}$ and axial force $\mathrm{N}$ applied to the 
cross-section at mid-height is $\mathrm{M}=\mathrm{Ne}=\mathrm{N}\left(\omega_{i}+\mathrm{e}_{i}+\mathrm{e}^{\prime}\right)$, where $\mathrm{e}$ is the total eccentricity comprising the initial eccentricity, $\left(\omega_{i}+e_{i}\right)$, and the eccentricity generated due to second order effects, $e^{\prime}$. The bending moment and the compression force can be expressed in terms of the strain gauge readings by $\mathrm{M}=\mathrm{EI} \kappa$ $=\mathrm{EI}\left(\varepsilon_{\text {convex }}-\varepsilon_{\text {concave }}\right) / \mathrm{h}$ and $\mathrm{N}=\mathrm{EA}\left(\varepsilon_{\text {convex }}+\varepsilon_{\text {concave }}\right) / 2$, where $\varepsilon_{\text {convex }}$ and $\varepsilon_{\text {concave }}$ are the strain gauge readings on the convex and concave sides of the tube, respectively. By substituting the above expressions of $\mathrm{M}$ and $\mathrm{N}$ into $\mathrm{M}=\mathrm{N}\left(\omega_{\mathrm{i}}+\mathrm{e}_{\mathrm{i}}+\mathrm{e}^{\prime}\right)$ ), the relationship between the strain gauge readings and the initial eccentricity $\left(\omega_{i}+e_{i}\right)$ can be established, as shown in Equation (2), where $\psi$ is the ratio between $\varepsilon_{\text {convex }}$ and $\varepsilon_{\text {concave }}, \mathrm{e}^{\prime}$ is the second order eccentricity recorded by the string pot at the mid-height of the specimen and $I_{t}$ is the second moment of area of tube. For the grouted specimens, Equation (3) applies, where $A_{g}$ and $I_{g}$ are the cross-sectional area and the second moment of area of the grout, respectively and $E_{g m}$ is the grout secant modulus calculated according to Table 3 of EN 1992-1-1 [33]. It should be noted that the value of $\left(\omega_{i}+e_{i}\right)$ was established during the elastic stage of the tests.

$$
\begin{gathered}
\omega_{i}+e_{i}=\frac{2 I_{t}(1-\psi)}{A_{t} h(1+\psi)}-e^{\prime} \\
\omega_{i}+e_{i}=\frac{2\left(E_{t} I_{t}+E_{g m} I_{g}\right)(1-\psi)}{h\left(A_{t} E_{t}+A_{g} E_{g m}\right)(1+\psi)}-e^{\prime}
\end{gathered}
$$

\subsection{Experimental results}

\subsubsection{Tensile member test results}

The measured axial load-displacement curves from the tensile member tests are plotted in Figures 8 and 9 for the S460 and the S690 specimens, respectively. For the non-grouted specimens, where a load cell was used to measure the force in the cable during the test, the individual responses of the cable and the tube components, in addition to that of the cable-in-tube system, have also been presented. The key results obtained from the cable-in-tube tensile member tests, including the axial elastic stiffness $\mathrm{k}$, yield load $\mathrm{N}_{\mathrm{y}}$, elongation at yield load $\delta_{\mathrm{y}}$, ultimate load reached $\mathrm{N}_{\mathrm{u}}$ and elongation at ultimate load $\delta_{\mathrm{u}}$ of the tested systems are presented in Table 7 . The load in the cables at which fracture occured $\mathrm{N}_{\mathrm{uc}}$ are also given.

The load-deformation response of the cable-in-tube elements subjected to tensile loading can be predicted analytically [30]. Three possible cases of behaviour that could arise depending on the geometric and material properties of the tube and cable and the level of applied prestress, were considered; these included the tube yielding prior to the cable, the cable yielding prior to the tube and the cable and tube yielding simultaneously [30]. The cable-in-tube elements tested herein fell into the first case, where the tube yields prior to the cable. A full account of the derivation of the analytical expressions to describe the load-displacement response of members for these three cases is provided in [30], while a brief overview is given herein. The method was based on establishing the total potential energy function of the cable-in-tube system and differentiating with respect to the axial displacement to obtain the associated 
equilibrium path. For the case of the tube yielding prior to the cable, three stages of behaviour may be identified:

Stage 1: From the onset of loading until yielding of the tube. During this stage, both the tube and cable remain elastic and, assuming an elastic-perfectly plastic material stress-strain relationship for both the tube and cable, the equilibrium path of the load $\mathrm{N}$ versus axial displacement $\mathrm{x}$ of the system can be expressed by Equation (4), where $\mathrm{K}_{t}=\mathrm{A}_{\mathrm{t}} \mathrm{E}_{\mathrm{t}} / \mathrm{L}_{0}$ and $\mathrm{K}_{\mathrm{c}}=\mathrm{A}_{\mathrm{c}} \mathrm{E}_{\mathrm{c}} / \mathrm{L}_{\mathrm{c} 0}$ are the axial stiffness of the tube and cable, respectively, $\mathrm{L}_{0}$ and $\mathrm{L}_{\mathrm{c} 0}$ being the original lengths of the tube and cable prior to prestressing, $\mathrm{x}_{\mathrm{ty}}=\mathrm{f}_{\mathrm{ty}} \mathrm{L}_{0} / \mathrm{E}_{\mathrm{t}}$ is the yield displacement of the tube and $\mathrm{x}_{\mathrm{t}}=\mathrm{P}_{\mathrm{i}} / \mathrm{K}_{\mathrm{t}}$ is the compressive displacement of the tube arising from initial prestressing.

$$
\mathrm{N}=\left(\mathrm{K}_{\mathrm{c}}+\mathrm{K}_{\mathrm{t}}\right) \mathrm{x} \quad \text { for } \quad 0<\mathrm{x}<\mathrm{x}_{\mathrm{ty}}+\mathrm{x}_{\mathrm{t}}
$$

Stage 2: From the point at which the tube yields to the point at which the cable yields. During this stage, the tube undergoes plastic deformation, while the cable remains elastic, and the load-displacement relationship is given by Equation (5), where $\mathrm{x}_{\mathrm{cy}}=\mathrm{f}_{\mathrm{cy}} \mathrm{L}_{\mathrm{c} 0} / \mathrm{E}_{\mathrm{c}}$ is the yield displacement of the cable and $\mathrm{x}_{\mathrm{c}}=\mathrm{P}_{\mathrm{i}} / \mathrm{K}_{\mathrm{c}}$ is the tensile displacement of the cable arising from initial prestressing.

$$
N=\left(K_{c}+K_{t}\right)\left(x_{t y}+x_{t}\right)+K_{c}\left(x-x_{t y}-x_{t}\right) \text { for } x_{t y}+x_{t}<x<x_{c y}-x_{c}
$$

Stage 3: In this stage, both the tube and the cable have yielded and plastic deformation continues until either fracture of the tube at a displacement of $\mathrm{x}_{\mathrm{tf}}$, or more likely, of the cable at a displacement of $\mathrm{x}_{\mathrm{cf}}$ occurs. The load-displacement relationship is given by Equation (6).

$$
N=\left(K_{c}+K_{t}\right)\left(x_{t y}+x_{t}\right)+K_{c}\left(x_{c y}-x_{c}-x_{t y}-x_{t}\right) \quad \text { for } \quad x_{c y}-x_{c}<x<\min \left(x_{c f}-x_{c}, x_{t f}+x_{t}\right)
$$

Incorporating the measured geometric and material properties (with the measured stress-strain curves represented by an idealised elastic-perfectly plastic model) and the measured prestress loads into Equations (4)-(6), the analytical load-deformation curves for the S460 and S690 non-grouted specimens in the three stages can be generated, as plotted in Figures 10a and 10b. In the first stage (Equation (4)), the stiffness of the systems is provided by both of the tube and cable. After tube yielding, the system progresses into the second stage (Equation (5)), where only the cable contributes to the stiffness of the system. In the third stage (Equation (6)), where both the cable and tube have yielded, the system presents zero stiffness until one of the elements in the system fractures. Good agreement between the analytical curves from Equations (4)-(6) and the corresponding test results may be seen in Figure 10. 


\subsubsection{Compressive member test results}

Typical measured load-lateral deflection curves for the S460 and S690 compressive member tests are shown in Figure 11. The ultimate load reached $\mathrm{N}_{\mathrm{u}}$ for each of the tested cable-in-tube specimens is also reported in Table 8. Global buckling was the governing failure mode observed for both the non-grouted and grouted specimens, as illustrated in Figure 12. Analytical expressions based on second order elastic and second order rigid plastic models were developed and used to trace the load-lateral deflection response of the prestressed compressive elements. First, the elastic buckling load and yield load of the compressed prestressed elements were calculated. For the non-grouted members, Equation (7) gives the elastic buckling load $\mathrm{N}_{\mathrm{cr}}$, while Equation (8) gives the tube yield load $\mathrm{N}_{\text {ty }}$, taking into account the effect of the prestress load $\mathrm{P}_{\mathrm{i}}$. Equations (9) and (10) present the elastic buckling load, $\mathrm{N}_{\mathrm{cr}, \mathrm{g}}$, and yield load, accounting for the effect of prestress and grout, $\mathrm{N}_{\mathrm{ty}, \mathrm{g}}$, for the grouted members. While the presence of initial prestress deteriorates the tube yield strength, as has been accounted for in Equations (8) and (10), the elastic critical buckling load of the cable-in-tube system is independent of the initial prestress, as discussed and numerically verified in [1].

$$
\begin{gathered}
\mathrm{N}_{\mathrm{cr}}=\frac{\pi^{2} \mathrm{E}_{\mathrm{t}} \mathrm{I}_{\mathrm{t}}}{\mathrm{L}_{\mathrm{cr}}^{2}} \\
\mathrm{~N}_{\text {ty }}=\mathrm{A}_{\mathrm{t}} \mathrm{f}_{\mathrm{ty}}-\mathrm{P}_{\mathrm{i}} \\
\mathrm{N}_{\mathrm{cr}, \mathrm{g}}=\frac{\pi^{2}\left(\mathrm{E}_{\mathrm{t}} \mathrm{I}_{\mathrm{t}}+0.6 \mathrm{E}_{\mathrm{gm}} \mathrm{I}_{\mathrm{g}}\right)}{\mathrm{L}_{\mathrm{cr}}^{2}} \\
\mathrm{~N}_{\text {ty }, \mathrm{g}}=\mathrm{A}_{\mathrm{t}} \mathrm{f}_{\text {ty }}+\mathrm{A}_{\mathrm{g}} \mathrm{f}_{\mathrm{gk}}-\mathrm{P}_{\mathrm{i}}
\end{gathered}
$$

where $f_{g k}$ is the cylinder strength of the grout, determined in accordance with Table 3 of EN 1992-1-1 [33], and all other parameters are as previously defined.

The load-deflection relationship resulting from the second order elastic model is based on the assumption that the member has an initial sinusoidal imperfection of amplitude $\left(\omega_{i}+e_{i}\right)$, and is given by Equation (11), where $\omega_{\text {total }}$ is the total lateral deflection at mid-height measured from the straight configuration i.e. at $\mathrm{N}=0, \omega_{\text {total }}=\omega_{\mathrm{i}}+\mathrm{e}_{\mathrm{i}}$. The second order rigid plastic boundary was derived from the analysis of a concentrically loaded pin-ended column - see Figure 13. Once the axial load N is increased sufficiently beyond the point at which plasticity begins, a plastic hinge develops at the mid-height of the member. The axial load $\mathrm{N}$ that can be sustained under increased lateral deflection may be determined by considering the stress distribution across the plastic hinge, in the presence of prestress, as illustrated in Figure 14. The maximum stress is limited to the difference between the tube yield strength $f_{\text {ty }}$ and the initial prestress $f_{p}=P_{i} / A_{t}$, where the axial load N is resisted by the compressive region (Zone C2 in Figure 14) and the second order moment $\mathrm{M}=\mathrm{N} \omega_{\text {total }}$ is resisted by the two outer regions (Zones $\mathrm{C} 1$ and $\mathrm{T} 3$ in Figure 
14) which provide equal compressive and tensile forces that constitute the couple at the plastic hinge. As illustrated in Figures 11, the general test response may be characterised by envelopes that these two second order models create. In the early stages of loading, the test follows the elastic response given by Equation (11), until the onset of yielding, beyond which the response merges towards the plastic hinge model.

$$
\mathrm{N}=\mathrm{N}_{\mathrm{cr}}\left[\frac{\omega_{\text {total }}-\left(\omega_{\mathrm{i}}+\mathrm{e}_{\mathrm{i}}\right)}{\omega_{\text {total }}}\right]
$$

\section{Numerical modelling}

\subsection{Overview}

In order to examine the structural performance of high strength steel cable-in-tube systems further, a numerical modelling study was carried out in parallel with the experimental investigation. The components of the cable-in-tube members - the SHS tube, the prestressing cable, the connecting collars and the confined grout for the grouted specimens, were modelled in the nonlinear finite element analysis package ABAQUS [34] to replicate the test behaviour. The experimental results presented in Section 2 were used to validate the numerical models, which were subsequently used to perform parametric studies. Only compressive members were examined in the numerical study since the tensile behaviour of the members could be accurately captured through simple analytical models. Detailed descriptions of the developed FE models along with the results of the parametric study are described hereafter.

\subsection{Development of numerical models}

\subsubsection{Material modelling}

The measured material properties of the S460 and S690 steel tubes, prestressing cables and grout, presented in Section 2.2, were incorporated into the finite element models. The material properties of the steel tube and prestressing steel cable were specified in terms of true stress $\sigma_{\text {true }}$ and log plastic strain $\varepsilon_{\ln }^{\mathrm{pl}}$, which were derived from the measured engineering stress-strain responses, as defined in Equations (12) and (13), respectively, where $\sigma_{\text {nom }}$ is the engineering stress, $\varepsilon_{\text {nom }}$ is the engineering strain and $\mathrm{E}$ is the Young's modulus. The material model of the grout was derived based on the grout cube strength obtained from the tests, following the approach described in [35], where the elastic response and concrete damaged plasticity behaviour were defined. For the elastic behaviour, the Poisson's ratio was set equal to 0.2 and the modulus of elasticity was calculated according to ACI 318 [36]. Note that this yielded a modulus of elasticity for the grout of round $29000 \mathrm{MPa}$, which exceeds the minimum specified value of $20000 \mathrm{MPa}$ for the grout product employed in the tests. The concrete damaged plasticity model comprised three key aspects, namely the plasticity definition, the compressive behaviour and the tensile behaviour. The plasticity definition included the dilation angle $(\psi)$, the flow potential eccentricity (e), the ratio of the compressive strength under biaxial loading to that under uniaxial loading $\left(f_{b 0} / f_{c}^{\prime}\right)$, the ratio of the second stress invariant on the tensile meridian to that on the compressive meridian $(\mathrm{K})$ and 
the viscosity parameter; these parameters were defined following the approach developed in [35]. The compressive behaviour in the concrete damaged plasticity model was described by a uniaxial stress-strain curve based on the cylinder compressive strength of the grout [35], and consisting of a strain hardening slope, a short plateau and a softening response. For the tensile behaviour, a linear post-peak softening stress-strain curve was employed, with the tensile failure stress $f_{\mathrm{gt}}$ marking the end of the linear response, followed by the fracture energy $\left(G_{f}\right)$ characterising the tensile softening response. The values of $f_{g t}$ and $\mathrm{G}_{\mathrm{f}}$ were obtained as functions of the cylinder compressive strength in accordance with [33] and [37, 38], respectively.

$$
\begin{gathered}
\sigma_{\text {true }}=\sigma_{\text {nom }}\left(1+\varepsilon_{\text {nom }}\right) \\
\varepsilon_{\ln }^{\mathrm{pl}}=\ln \left(1+\varepsilon_{\text {nom }}\right)-\frac{\sigma_{\text {nom }}}{\mathrm{E}}
\end{gathered}
$$

\subsubsection{Boundary conditions and load application}

Owing to the symmetry in the geometry and boundary conditions of the tested cable-in-tube specimens, only half of the cross-section was modelled. The end-plates were modelled with rigid plates which were fixed to the ends of both the tube and the cable. For the grouted specimens, a friction coefficient of 0.25 was used to model the contact between the tube-to-grout and the grout-to-cable interfaces in the tangential direction while a hard contact was defined in the normal direction. The effect of the connecting collars in the non-grouted members was modelled by means of the *EQUATION command in ABAQUS [34], where the movement of the cable at the collar positions and its corresponding node on the tube in the direction of the buckling axis were equated. The axial load was applied through two reference points which were coupled to the end-plates at each ends. The distance between the reference points was set equal to the total buckling length of the specimens, taking into consideration the height of the knife edges and the cylinders, as shown in Figure 7a. Displacement control was used to apply the compressive load to the cable-in-tube systems. Prior to the application of the external compressive loading, the initial prestress was applied by assigning initial stresses to the cable and the tube using the *INITIAL CONDITIONS keyword command in ABAQUS [34]. The applied initial stresses in the cable and the tube were determined by dividing the measured prestress force, reported in Table 6 , by the cross-sectional area of the cable and tube, respectively. The initial stresses applied were then self-balanced in a *STATIC GENERAL step.

\subsubsection{Geometric imperfections, residual stresses and mesh type}

An initial imperfection in the form of the lowest global buckling mode, obtained from a linear elastic eigenvalue buckling analysis, with the amplitudes $\left(\omega_{i}+e_{i}\right)$ reported in Table 6 were assigned to the

numerical models. Residual stresses were not explicitly incorporated into the models due to their low measured amplitudes and minimal influence on the member compressive resistance [39]. The three-dimensional 
eight noded solid element C3D8 was used to model all the components of the cable-in-tube specimens. The basic mesh size was $\mathrm{t}$ (width) $\times 2 \mathrm{t}$ (depth) $\times \mathrm{t}$ (length), where $\mathrm{t}$ is the cross-section thickness of the steel tube, as also adopted in other similar studies [1,40].

\subsection{Validation results and parametric study}

The developed numerical models were able to capture accurately the observed load-deformation history of the prestressed members under external compressive loading. This is shown in Figures 15a and 15b, where the load-lateral deflection curves derived from the numerical models of the C460NG0 and C460G0 members are compared with their respective test responses. A summary of the comparisons between the test and FE results in terms of the ultimate load reached is provided in Table 9. The models give a mean FE/test ultimate load of 0.96 and a coefficient of variation of 0.067. The C690G0 and C690G2 members showed the largest deviation between the test and FE ultimate loads; this may be attributed to the test specimens having lower imperfections were determined from the strain gauge calculations described in Section 2.4, as indicated by a high initial slope to the load-lateral deflection curves. Overall, however, good agreement between the test and FE results was achieved. Based on the validated numerical models, an extensive parametric study was conducted for the development and assessment of design proposals. A total of 192 parametric FE simulations were made, comprising 8 member slenderness values (0.5-2.25), 2 cable sizes $\left(\mathrm{A}_{\mathrm{c}}=100\right.$ and $\left.150 \mathrm{~mm}^{2}\right), 3$ prestress levels $\left(\mathrm{P}_{\text {nom }}, 0.5 \mathrm{P}_{\text {opt }}\right.$ and $\left.\mathrm{P}_{\text {opt }}\right), 2$ grout conditions (grouted and non-grouted) and 2 steel grades (S460 and S690). An initial global imperfection amplitude of $\mathrm{L}_{\mathrm{cr}} / 1000$, where $\mathrm{L}_{\mathrm{cr}}$ is the column buckling length, was applied to all the models; this is in accordance with the permitted out-of-straightness tolerance in EN 1090-2 [41]. This imperfection amplitude was also adopted in the development of the EN 1993-1-1 column buckling curves [42, 43].

\section{Analysis of results}

\subsection{Influence of prestress, grout and steel grade on the tensile behaviour}

The overall tensile responses of the tested S460 and S690 cable-in-tube specimens are presented in Figures 16 and 17, respectively, where the influences of addition of a prestressing cable, increasing prestress levels and the use of grout may be observed. From the comparison of the results of the T460NGN and T460NG0 specimens and the T690NGN and T690NG0 specimens, it is clear that the introduction of prestressing cables can significantly improve the strength of the cable-in-tube systems. This is essentially due to the fact that the prestressing cable, with a fracture load of approximately 270 $\mathrm{kN}$, will also contribute in resisting the applied tensile load. In all cases, the measured cable fracture loads are very close (see Table 7) to the predicted value of $270 \mathrm{kN}$, which is the product of the cable cross-sectional area and its ultimate tensile strength. As illustrated by specimens T460NG1, T460NG2, T690NG1 and T690NG2, increasing the level of initial prestress level, which delays the yielding of the tube and brings it closer to the yielding point of the prestressing cable, increases the extent of the elastic region of the system's response. This increase in the range of the elastic response reduces the axial 
deflection required to reach the ultimate load. Note that, as expected, the pre-yielding axial stiffness of the cable-in-tube system remains approximately constant with increasing prestress level. The presence of grout, as observed in specimens T460G1, T460G2, T690G1 and T690G2 members, had a minimal effect on the tensile strength of the cable-in-tube systems, but was found to improve their ductility. As expected, the S690 specimens exhibited higher tensile resistances than the S460 specimens, but the lower steel grade members benefit to a greater extent from the addition of cables and prestressing.

\subsection{Influence of prestress, grout and steel grade on the compressive behaviour}

The overall load-lateral deflection responses obtained from the compressive tests are plotted in Figure 18 for the S460 members and Figure 19 for the S690 members. The detrimental effect of prestressing on the compressive capacity of cable-in-tube systems is evident from the test results in Figures 18 and 19, where a trend of lower compressive resistance with higher prestress level is generally displayed. However, the observed reduction in resistance is relatively small compared to the applied initial preload. For example, in Figures 18 and 19, the C460NG2 member had an initial preload $\mathrm{P}_{\mathrm{i}}$ of $125.6 \mathrm{kN}$ but a reduction in resistance of only $48.2 \mathrm{kN}$ compared with the C460NG0 member, which had an initial preload of 6.8 $\mathrm{kN}$, and the capacity of the C690NG0 $\left(\mathrm{P}_{\mathrm{i}}=3.7 \mathrm{kN}\right)$ was almost the same as the C690NG2 $\left(\mathrm{P}_{\mathrm{i}}=120.8 \mathrm{kN}\right)$ member. This can be explained by noting (i) that some of the initial preload is relieved due to shortening of the cable-in-tube system under the application of external loading and (ii) the absence of second order bending moments induced by prestressing i.e. the prestress force remains aligned with the centroidal axis of the member, even in the deformed configuration. The presence of grout was shown, as expected, to increase the compressive capacity of the cable in tube specimens, though the enhancement in strength was relatively small due to the slender nature of the test specimens. As noted previously, the two specimens C690G0 and C690G2 deviated somewhat from the anticipated trends, perhaps due to very low initial imperfections.

\section{Design recommendations}

\subsection{Design of tensile members}

The tensile behaviour of cable-in-tube systems can be accurately predicted through the simple analytical models described in [1], as illustrated in Figure 10. Taking failure to be the point at which the tube yields in tension, the tensile resistance $\mathrm{N}_{\mathrm{t}, \mathrm{Rd}}$ of a prestressed element is given by Equation (14). This corresponds to the load at which there is a sharp change in the slope of the load versus displacement response of the system, as shown in Figure 10. Increasing $\mathrm{P}_{\mathrm{i}}$ delays yielding of the tube hence results in increased resistance. It should be noted that the initial applied prestress level $\mathrm{P}_{\mathrm{i}}$ should not exceed the minimum of the optimum design prestress level $\mathrm{P}_{\mathrm{opt}, \mathrm{d}}$, the design tube yield load $\mathrm{A}_{\mathrm{t}} \mathrm{f}_{\mathrm{ty}} / \gamma_{\mathrm{M} 0}$ or the

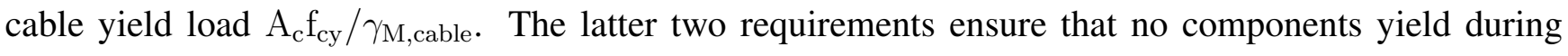
prestressing. Owing to its minimal influence in tension, the effect of grout has not been taken into account 
in Equation (14). The load-sharing between the cable and tube is accounted for through the $\left(1+\frac{E_{c} A_{c}}{E_{t} A_{t}}\right)$ term which relates to the stiffness of the two components. To avoid non-ductile failure through cable fracture, a suitable partial factor $\gamma_{\mathrm{M} \text {,cable }}$ is applied to the cable in Equation (14), with a recommended value of 1.5 [44]. Similarly, Equation (1) is modified to give the design value of the optimum prestress, $\mathrm{P}_{\mathrm{opt}, \mathrm{d}}$, as set out in Equation (15). The use of Equations (14) and (15) ensures that the stress in the cable does not exceed $\mathrm{f}_{\mathrm{cy}} / \gamma_{\mathrm{M} \text {,cable }}$ before the tube yielding.

$$
\begin{gathered}
\mathrm{N}_{\mathrm{t}, \mathrm{Rd}}=\left(\frac{\mathrm{A}_{\mathrm{t}} \mathrm{f}_{\mathrm{ty}}}{\gamma_{\mathrm{M} 0}}+\mathrm{P}_{\mathrm{i}}\right)\left(1+\frac{\mathrm{E}_{\mathrm{c}} \mathrm{A}_{\mathrm{c}}}{\mathrm{E}_{\mathrm{t}} \mathrm{A}_{\mathrm{t}}}\right) \quad \text { but } \quad \mathrm{P}_{\mathrm{i}} \leqslant \min \left(\mathrm{P}_{\mathrm{opt}, \mathrm{d}}, \frac{\mathrm{A}_{\mathrm{t}} \mathrm{f}_{\mathrm{ty}}}{\gamma_{\mathrm{M} 0}}, \frac{\mathrm{A}_{\mathrm{c}} \mathrm{f}_{\mathrm{cy}}}{\gamma_{\mathrm{M}, \mathrm{cable}}}\right) \\
\mathrm{P}_{\mathrm{opt}, \mathrm{d}}=\frac{\mathrm{A}_{\mathrm{t}} \mathrm{A}_{\mathrm{c}}}{\mathrm{A}_{\mathrm{t}} \mathrm{E}_{\mathrm{t}}+\mathrm{A}_{\mathrm{c}} \mathrm{E}_{\mathrm{c}}}\left(\frac{\mathrm{f}_{\mathrm{cy}}}{\gamma_{\mathrm{M}, \mathrm{cable}}} \mathrm{E}_{\mathrm{t}}-\frac{\mathrm{f}_{\mathrm{ty}}}{\gamma_{\mathrm{M} 0}} \mathrm{E}_{\mathrm{c}}\right)
\end{gathered}
$$

Comparisons between the predicted tensile resistances (from Equation (14)) and the tensile yield loads from the member tests $\mathrm{N}_{\mathrm{y} \text {,test }}$ are presented in Table 10. Note that the measured geometric and material properties have been employed in these comparisons and all partial factors have been set equal to unity. The predictions may be seen to be generally accurate, with an average $\mathrm{N}_{\mathrm{y}, \text { test }} / \mathrm{N}_{\mathrm{t}, \mathrm{Rd}}$ ratio of 0.99 and coefficient of variation (COV) of 0.05 .

\subsection{Design of compressive members}

The design of cable-in-tube systems in compression was studied by Gosaye et al. [1], where a method based on the Perry-Robertson approach [45] for conventional column design was developed, termed the modified Perry-Roberston approach, which was then presented in the framework of the Eurocode 3 buckling curves [1]. The development of the method leading to the establishment of the design resistance expressions for prestressed elements under compression and comparisons with the test and numerical results obtained herein, are presented in the following sub-sections.

\subsubsection{Development of modified Perry-Robertson method}

Considering an imperfect pin-ended compressed member, the maximum stress at the critical mid-height cross-section of a non-grouted prestressed cable-in-tube system $\sigma_{\max }$ comprises an axial stress, a bending stress and a prestress term, as given by Equation (16), where $\mathrm{N}$ is the applied compressive force, $\mathrm{M}$ is the bending moment at mid-height, $d$ is the distance from the neutral axis to the extreme fibre of the tube and $\mathrm{P}$ is the prestress force. Note that the prestress force $\mathrm{P}$ reduces from its initial value $\mathrm{P}_{\mathrm{i}}$ under the application of the compressive load $\mathrm{N}$ following the relationship given by Equation (17), which was derived in [1]. In Equation (17), $K_{t}$ is the axial stiffness of the tube and $K_{c}$ is the axial stiffness of the cable, as previously defined in Section 2.5.1. Following a similar approach to Ayrton and Perry [45] (i.e. limiting the maximum stress $\sigma_{\max }$ to the yield stress of the tube $f_{t y}$ ), the average applied stress $\left(\sigma_{\mathrm{b}}=\mathrm{N}_{\mathrm{b}} / \mathrm{A}_{\mathrm{t}}\right)$ to cause first yield on the concave side of the member is as expressed by Equation 
(18). In Equation (18), $\alpha_{\mathrm{k}}$ is the ratio of the axial stiffness of the tube to that of the cable-in-tube system $\alpha_{\mathrm{k}}=\mathrm{K}_{\mathrm{t}} /\left(\mathrm{K}_{\mathrm{c}}+\mathrm{K}_{\mathrm{t}}\right)$, $\mathrm{f}_{\mathrm{P}}$ is the initial prestress $\left(\mathrm{P}_{\mathrm{i}} / \mathrm{A}_{\mathrm{t}}\right), \sigma_{\mathrm{E}}$ is the elastic buckling stress of the tube $\left(\mathrm{N}_{\mathrm{cr}} / \mathrm{A}_{\mathrm{t}}\right)$ and $\eta$ is an imperfection parameter, defined as $\eta=\mathrm{dA}_{\mathrm{t}}\left(\omega_{\mathrm{i}}+\mathrm{e}_{\mathrm{i}}\right) / \mathrm{I}_{\mathrm{t}}$. Relating the imperfection parameter $\eta$ to the slenderness of the member, the Perry-Robertson expression, in the form adopted in Eurocode 3 for the design of compression members, is obtained; this is discussed in the following section.

$$
\begin{gathered}
\sigma_{\max }=\frac{\mathrm{N}}{\mathrm{A}_{\mathrm{t}}}+\frac{\mathrm{Md}}{\mathrm{I}_{\mathrm{t}}}+\frac{\mathrm{P}}{\mathrm{A}_{\mathrm{t}}} \\
\mathrm{P}=\mathrm{P}_{\mathrm{i}}-\left[\frac{\mathrm{K}_{\mathrm{c}}}{\mathrm{K}_{\mathrm{c}}+\mathrm{K}_{\mathrm{t}}}\right] \mathrm{N} \\
\sigma_{\mathrm{b}}=\frac{\left[\mathrm{f}_{\mathrm{ty}}+\left(\alpha_{\mathrm{k}}+\eta\right) \sigma_{\mathrm{E}}-\mathrm{f}_{\mathrm{P}}\right]}{2 \alpha_{\mathrm{k}}}-\frac{1}{2 \alpha_{\mathrm{k}}} \sqrt{\left[\mathrm{f}_{\mathrm{ty}}+\left(\alpha_{\mathrm{k}}+\eta\right) \sigma_{\mathrm{E}}-\mathrm{f}_{\mathrm{P}}\right]^{2}-4 \sigma_{\mathrm{E}} \alpha_{\mathrm{k}}\left(\mathrm{f}_{\mathrm{ty}}-\mathrm{f}_{\mathrm{P}}\right)}
\end{gathered}
$$

\subsubsection{Proposed design approach and comparison of results}

The modified Perry-Robertson approach described above may be presented in the form of the Eurocode 3 buckling curves by adopting the EN 1993-1-1 [46] imperfection parameter $\eta$ given by Equation (19). In Equation (19), $\bar{\lambda}$ is the member slenderness defined as $\bar{\lambda}=\sqrt{\mathrm{N}_{\mathrm{pl}} / \mathrm{N}_{\mathrm{cr}}}$, where $\mathrm{N}_{\mathrm{pl}}$ is the tube yield load $\left(\mathrm{N}_{\mathrm{pl}}=\mathrm{A}_{\mathrm{t}} \mathrm{f}_{\mathrm{ty}}\right), \mathrm{N}_{\mathrm{cr}}$ is the elastic buckling load of the tubular member) and $\alpha$ is the imperfection factor which takes on discrete values to represent the different buckling curves.

$$
\eta=\alpha(\bar{\lambda}-0.2)
$$

Using the imperfection parameter of Equation (19), the compressive resistance of a non-grouted cable-in-tube system $\mathrm{N}_{\mathrm{b}, \mathrm{Rd}}$ may be obtained by means of Equation (18) as the product of the reduction factor $\chi_{\mathrm{p}}$ and the cross-section yield load $\mathrm{N}_{\mathrm{pl}}$; the result is given by Equation (20).

$$
\mathrm{N}_{\mathrm{b}, \mathrm{Rd}}=\frac{\chi_{\mathrm{p}} \mathrm{N}_{\mathrm{pl}}}{\gamma_{\mathrm{M} 0}}
$$

where $\gamma_{\mathrm{M} 0}$ is a partial safety factor, and $\chi_{\mathrm{p}}$ is given by:

$$
\chi_{\mathrm{p}}=\frac{1-\mathrm{P}_{\mathrm{i}} / \mathrm{N}_{\mathrm{pl}}}{\alpha_{\mathrm{k}}\left[\phi_{\mathrm{p}}+\sqrt{\phi_{\mathrm{p}}^{2}-\left(1-\mathrm{P}_{\mathrm{i}} / \mathrm{N}_{\mathrm{pl}}\right) \bar{\lambda}^{2} / \alpha_{\mathrm{k}}}\right]}
$$

with $\phi_{\mathrm{p}}$ defined as:

$$
\phi_{\mathrm{p}}=\frac{\left(1-\mathrm{P}_{\mathrm{i}} / \mathrm{N}_{\mathrm{pl}}\right) \bar{\lambda}^{2}+\alpha_{\mathrm{k}}+\eta}{2 \alpha_{\mathrm{k}}}
$$

The compressive capacity of grouted cable-in-tube members can be determined based on a similar approach, but with modifications made to the cross-section capacity and member slenderness to account 
for the presence of the grout. Equations (23) and (24) have been adopted from EN 1994-1-1 [47] to calculate the cross-section capacity $\mathrm{N}_{\mathrm{pl}, \mathrm{g}}$ and member slenderness $\bar{\lambda}_{\mathrm{g}}$, respectively. To account for the influence of the grout on the axial stiffness of the system, the term $\alpha_{\mathrm{k}}$ in Equations (21) and (22) has been replaced by that given in Equation (25). It should be noted that for very small initial prestress values $\mathrm{P}_{\mathrm{i}} \leqslant \mathrm{N}_{\mathrm{b} \text {,tube }} \mathrm{K}_{\mathrm{c}} /\left(\mathrm{K}_{\mathrm{c}}+\mathrm{K}_{\mathrm{t}}\right)$ for non-grouted members and $\mathrm{P}_{\mathrm{i}} \leqslant \mathrm{N}_{\mathrm{b} \text {,tube,g}} \mathrm{K}_{\mathrm{c}} /\left(\mathrm{K}_{\mathrm{c}}+\mathrm{K}_{\mathrm{t}}+\mathrm{K}_{\mathrm{g}}\right)$ for grouted members, where $\mathrm{N}_{\mathrm{b} \text {,tube }}$ and $\mathrm{N}_{\mathrm{b} \text {,tube,g }}$ are the buckling resistances of the steel tube and grouted steel tube, respectively - the cable will slacken before the member fails. Hence the design is equivalent to the case with no prestress, which can be account for by taking $\mathrm{P}_{\mathrm{i}}=0$ and $\alpha_{\mathrm{k}}=1$ in Equations (21) and (22).

$$
\begin{gathered}
\mathrm{N}_{\mathrm{pl}, \mathrm{g}}=\mathrm{A}_{\mathrm{t}} \mathrm{f}_{\mathrm{ty}}+\mathrm{A}_{\mathrm{g}} \mathrm{f}_{\mathrm{gk}} \\
\bar{\lambda}_{\mathrm{g}}=\sqrt{\frac{\mathrm{N}_{\mathrm{pl}, \mathrm{g}}}{\mathrm{N}_{\mathrm{cr}, \mathrm{g}}}} \\
\alpha_{\mathrm{k}, \mathrm{g}}=\frac{\mathrm{K}_{\mathrm{t}}+\mathrm{K}_{\mathrm{g}}}{\mathrm{K}_{\mathrm{c}}+\mathrm{K}_{\mathrm{t}}+\mathrm{K}_{\mathrm{g}}}
\end{gathered}
$$

where $\mathrm{K}_{\mathrm{g}}=\mathrm{E}_{\mathrm{gm}} \mathrm{A}_{\mathrm{g}} / \mathrm{L}$.

The developed design resistance expressions may be used in conjunction with the Eurocode 3 buckling curves to predict the compressive resistance of high strength steel cable-in-tube members. A total of five buckling curves, $\mathrm{a}_{0}, \mathrm{a}, \mathrm{b}, \mathrm{c}$ and $\mathrm{d}$, characterised by the imperfection factors $\alpha$ of $0.13,0.21,0.34$, 0.49, and 0.76, respectively, are adopted in EN 1993-1-1. The influences of geometric imperfections, residual stresses and load eccentricity on the predicted compressive capacity is implicitly accounted for through the imperfection factor associated with each of the buckling curves. In Eurocode 3, selection of the appropriate buckling curve depends on the cross-section shape and geometric proportions, the manufacturing process, the axis of buckling and the steel grade. Two buckling curves are proposed herein for hot-finished high strength steel cable-in-tube systems, depending on the effective yield stress of the steel tube $f_{\text {ty, eff }}$, defined as the tube yield stress $f_{t y}$ minus the applied prestress $-P_{i} / A_{t}$. For hot-finished tubular members with $\mathrm{f}_{\mathrm{ty} \text {,eff }} \geqslant 460 \mathrm{~N} / \mathrm{mm}^{2}$, buckling curve $\mathrm{a}_{0}$ with $\alpha=0.13$ is proposed, while for those with $\mathrm{f}_{\mathrm{ty} \text {,eff }}<460 \mathrm{~N} / \mathrm{mm}^{2}$, buckling curve a with $\alpha=0.21$ is recommended. This approach has been adopted because the application of prestress effectively reduces the yield strength of the tube and, as for conventional steel design, columns of lower strength material $\left(f_{y}<460 \mathrm{~N} / \mathrm{mm}^{2}\right)$ are assigned a lower buckling curve than those higher strength material due to the higher sensitivity to geometric imperfections and the residual stresses being a higher proportion of the yield strength.

In order to assess the accuracy of the proposed design method, the predicted resistances have been compared with their respective experimental and numerical capacities and a summary of the obtained results is reported in Table 11. Comparisons are also presented against existing test data on prestressed 
cold-formed S235 steel specimens with the corresponding predictions made using the same approach but with different buckling curves as described in [1]; the results are also shown in Table 11. The mean test to predicted capacity ratio $\mathrm{N}_{\mathrm{u} \text {, test }} / \mathrm{N}_{\mathrm{b}, \mathrm{Rd}}$, excluding the FE data, is 0.99 for the $\mathrm{S} 460$ material, 1.06 for the S690 material and 1.02 for the S235 material. Considering both test and FE results, the mean ratio of test or FE to predicted capacity is 1.03 for the S460 material, 1.05 for the S690 material and 1.07 for the S235 material. In all cases, the scatter (COV) is less than 10\%. Graphical comparisons between the predicted design resistances and the FE capacities are also provided in Figures 20a and 20b, where the C460NG $\left(\mathrm{A}_{\mathrm{c}}=100 \mathrm{~mm}^{2}\right)$ and $\mathrm{C} 690 \mathrm{G}\left(\mathrm{A}_{\mathrm{c}}=150 \mathrm{~mm}^{2}\right)$ member results are given as examples; the comparisons show that the FE results closely follow the general pattern of the buckling curves, and confirms the applicability of the proposed design approach.

\section{Conclusions}

The tensile and compressive behaviour of cable-in-tube systems has been examined through a series of experimental and numerical investigations in this paper. A total of 12 S460 and S690 cable-in-tube members in tension and 10 in compression were tested. Numerical models, validated against the experimental results, were developed for the members in compression, and subsequently employed in parametric studies considering a wider range of geometries. The tensile resistance was shown to be enhanced by the addition of the cable while the application of prestress was needed to extend the elastic range and hence the overall performance of the cable-in-tube system. Prestressing was found to reduce the compressive resistance of the system, but the reduction in strength was less than the applied prestress due primarily to the absence of second order bending moments associated with the prestressing force. A design method for cable-in-tube systems in tension was established based on a simple analytical model featuring the relative stiffnesses of the component parts, and was shown to give accurate predictions of the tensile test results. In compression, a modified Perry-Robertson design approach was adopted with the selection of buckling curve following the EC 3 recommendations but based on an effective yield strength to account for the yield strength reduction due to the application of prestress. Comparisons with the test and FE results confirmed the accuracy and applicability of the proposed approach.

\section{Acknowledgements}

The research leading to these results has received funding from the Research Fund for Coal and Steel (RFCS) under grant agreement No. RFSR CT 2012-00028. V\& M DEUTSCHLAND GMBH is acknowledged

for the supply of the test specimens. The authors are indebted to Mr. Gordon Herbert, Mr. Paras Shah and Mr Stephen Okeghie for their assistance during the tests. 


\section{List of symbols}

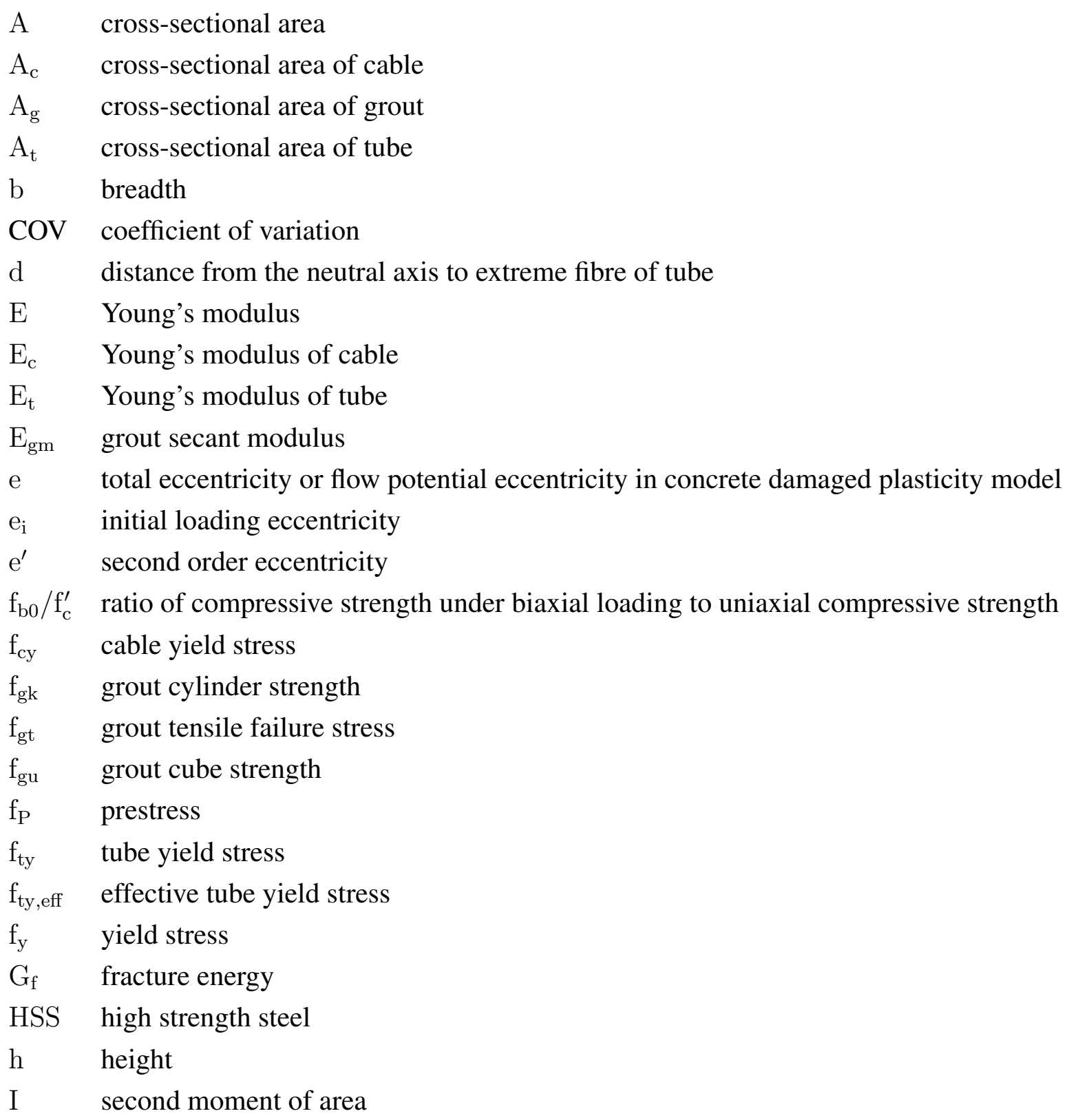




$\begin{array}{ll}\mathrm{I}_{\mathrm{g}} & \text { grout second moment of area } \\ \mathrm{I}_{\mathrm{t}} & \text { tube second moment of area } \\ \mathrm{K} & \text { compressive meridian } \\ \mathrm{K}_{\mathrm{c}} & \text { axial stiffness of cable } \\ \mathrm{K}_{\mathrm{g}} & \text { axial stiffness of grout } \\ \mathrm{K}_{\mathrm{t}} & \text { axial stiffness of tube } \\ \mathrm{k} & \text { axial stiffness } \\ \mathrm{L} & \text { length } \\ \mathrm{L}_{\mathrm{cr}} & \text { buckling length } \\ \mathrm{L}_{\mathrm{c} 0} & \text { length of cable before prestressing } \\ \mathrm{L}_{0} & \text { length of tube before prestressing } \\ \mathrm{M} & \text { moment } \\ \mathrm{N}_{\mathrm{N}} & \text { axial force } \\ \mathrm{N}_{\mathrm{b}, \text { tube }} & \text { buckling load of steel tube with no prestressing } \\ \mathrm{N}_{\mathrm{b}, \text { tube,g }} & \text { buckling load of grouted steel tube with no prestressing } \\ \mathrm{N}_{\mathrm{b}, \mathrm{Rd}} & \text { design buckling resistance } \\ \mathrm{N}_{\mathrm{cr}} & \text { elastic buckling load of non-grouted member } \\ \mathrm{N}_{\mathrm{cr}, \mathrm{g}} & \text { elastic buckling load of grouted member } \\ \mathrm{N}_{\mathrm{cu}} & \text { fracture load of cable } \\ \mathrm{N}_{\mathrm{pl}} & \text { plastic resistance of non-grouted member } \\ \mathrm{N}_{\mathrm{pl}, \mathrm{g}} & \text { plastic resistance of grouted member } \\ \mathrm{N}_{\mathrm{t}, \mathrm{Rd}} & \text { design tensile resistance of cable-in-tube system } \\ \mathrm{N}_{\mathrm{ty}} & \text { tube yield load of non-grouted member accounting for the effect of prestress } \\ \mathrm{N}_{\mathrm{ty}, \mathrm{g}} & \text { tube yield load of grouted member accounting for the effect of prestress and grout } \\ \mathrm{N}_{\mathrm{u}} & \text { ultimate load } \\ \mathrm{N}_{\mathrm{u}, \text { test }} & \text { test ultimate load } \\ \mathrm{N}_{\mathrm{u}, \mathrm{FE}} & \text { FE ultimate load } \\ \end{array}$




\begin{tabular}{|c|c|}
\hline $\mathrm{N}_{\mathrm{y}}$ & tensile yield load of cable-in-tube system \\
\hline $\mathrm{N}_{\mathrm{y}, \text { test }}$ & test tensile yield load of cable-in-tube system \\
\hline $\mathrm{P}$ & prestress force \\
\hline $\mathrm{P}_{\mathrm{i}}$ & initial prestress force \\
\hline $\mathrm{P}_{\text {nom }}$ & nominal prestress force \\
\hline $\mathrm{P}_{\text {opt }}$ & optimum prestress force \\
\hline $\mathrm{P}_{\mathrm{opt}, \mathrm{d}}$ & design value of optimum prestress force \\
\hline $\mathrm{r}_{\mathrm{ex}}$ & external corner radius \\
\hline SHS & square hollow section \\
\hline $\mathrm{t}$ & thickness \\
\hline $\mathrm{x}$ & axial displacement of cable in tube system \\
\hline $\mathrm{x}_{\mathrm{c}}$ & axial tensile displacement of cable arising from prestressing \\
\hline $\mathrm{x}_{\mathrm{cf}}$ & fracture displacement of cable \\
\hline $\mathrm{x}_{\mathrm{cy}}$ & yield displacement of cable \\
\hline $\mathrm{x}_{\mathrm{t}}$ & axial compressive displacement of tube arising from prestressing \\
\hline $\mathrm{x}_{\mathrm{tf}}$ & fracture displacement of tube \\
\hline $\mathrm{x}_{\mathrm{ty}}$ & yield displacement of tube \\
\hline$\alpha$ & imperfection factor \\
\hline$\alpha_{\mathrm{k}}$ & axial stiffness ratio in non-grouted member \\
\hline$\alpha_{\mathrm{k}, \mathrm{g}}$ & axial stiffness ratio in grouted member \\
\hline$\delta_{\mathrm{u}}$ & elongation at ultimate load \\
\hline$\delta_{\mathrm{y}}$ & elongation at yield load \\
\hline$\varepsilon_{\text {concave }}$ & strain on concave side of cross-section \\
\hline$\varepsilon_{\text {convex }}$ & strain on convex side of cross-section \\
\hline$\varepsilon_{\text {eng }}$ & engineering strain \\
\hline$\varepsilon_{\ln }^{\mathrm{pl}}$ & logarithmic plastic strain \\
\hline$\eta$ & imperfection parameter \\
\hline $\bar{\lambda}$ & member slenderness \\
\hline $\bar{\lambda}_{\mathrm{g}}$ & slenderness of grouted member \\
\hline
\end{tabular}




$\begin{array}{ll}\sigma_{\mathrm{b}} & \text { buckling stress } \\ \sigma_{\mathrm{E}} & \text { elastic buckling stress of tube } \\ \sigma_{\mathrm{eng}} & \text { engineering stress } \\ \sigma_{\mathrm{max}} & \text { maximum stress at critical section } \\ \sigma_{\text {true }} & \text { true stress } \\ \gamma_{\mathrm{M} 0} & \text { partial safety factor } \\ \gamma_{\mathrm{M}, \mathrm{cable}} & \text { partial safety factor for cable } \\ \chi_{\mathrm{p}} & \text { buckling reduction factor for prestressed member } \\ \psi & \text { ratio of stresses or strains across section depth } \\ \psi & \text { dilation angle } \\ \omega_{\mathrm{i}} & \text { global imperfection amplitude } \\ \omega_{\text {total }} & \text { total lateral deflection at mid-height }\end{array}$

\section{References}

[1] Gosaye J., Gardner L., Wadee M. A., and Ellen M. E. Compressive behaviour and design of prestressed steel elements. Structures, 5:76-87, 2016.

[2] Ellen P. E. Post-tensioned steel structure, 1987. Patent. No. US 4676045 A.

[3] Wang J. Behaviour and design of high strength steel structures. PhD thesis, Department of Civil and Environmental Engineering, Imperial College London, 2016.

[4] Han K. and Park S. Parametric study of truss bridges by the posttensioning method. Canadian Journal of Civil Engineering, 32:420-429, 2005.

[5] Magnel G. Prestressed steel structures. The Structural Engineer, 28:285-295, 1950.

[6] Ayyub B. M. and Ibrahim A. Post-tensioned trusses: reliability and redundancy. Journal of Structural Engineering, ASCE, 116(6):1507-1521, 1990.

[7] Ayyub B. M., Ibrahim A., and Schelling D. Posttensioned truss: analysis and design. Journal of Structural Engineering, ASCE, 116(6):1491-1506, 1990.

[8] Finn E. V. and Needham F. H. The use of prestressed steel in elevated roadways. The Structural Engineer, 42(1):5-18, 1964.

[9] Clarke M. J. and Hancock G. J. Finite-element nonlinear analysis of stressed-arch frames. Journal of Structural Engineering, ASCE, 117(10):2819-2837, 1991.

[10] Lee K. and Han S. Analysis of the stress-erection process of strarch frames considering the joint connection properties. Journal of Constructional Steel Research, 92:195-210, 2014. 
[11] Lee K., Huque Z., and Han S. Analysis of stabilizing process for stress-erection of strarch frame. Engineering Structures, 59:49-67, 2014.

[12] Hancock G. J., Key P., and Olsen C. J. Structural behaviour of a stressed arch structural system. In Ninth International Specialty Conference on Cold-Formed Steel Structures, pages 557-569, 1988.

[13] Clarke M. J. and Hancock G. J. Simple design procedure for cold-formed tubular top chord of stressed-arch frames. Engineering Structures, 16(5):377-385, 1994.

[14] Clarke M. J. and Hancock G. J. Tests and nonlinear analysis of small-scale stressed-arch frames. Journal of Structural Engineering, ASCE, 121(2):187-200, 1995.

[15] Gosaye J. Behaviour and design of prestressed steel structures. PhD thesis, Department of Civil and Environmental Engineering, Imperial College London, 2015.

[16] Li H. and Schmidt L. C. Post-tensioned and shaped hypar space trusses. Journal of Structural Engineering, ASCE, 123(2):130-137, 1997.

[17] Schmidt L. C. and Li H. Studies on post-tensioned and shaped space-truss domes. Structural Engineering and Mechanics, 6:693-710, 1998.

[18] Reagan R. S. and Krahl N. W. Behavior of prestressed composite beams. Journal of the Structural Division, ASCE, 93(6):87-108, 1967.

[19] Klaiber F. W., Dunker K. F., and Sanders W. W. Strengthening of single-span steel-beam bridges. Journal of the Structural Division, ASCE, 108(12):2766-2780, 1982.

[20] Saadatmanesh H., Albrecht P., and Ayyub B. M. Experimental study of prestressed composite beams. Journal of Structural Engineering, ASCE, 115(9):2348-2364, 1989.

[21] Saadatmanesh H., Albrecht P., and Ayyub B. M. Analytical study of prestressed composite beams. Journal of Structural Engineering, ASCE, 115(9):2364-2381, 1989.

[22] Saadatmanesh H., Albrecht P., and Ayyub B. M. Guidelines for flexural design of prestressed composite beams. Journal of Structural Engineering, ASCE, 115(11):2944-2961, 1989.

[23] Ayyub B. M., Sohn Y. G., and Saadatmanesh H. Prestressed composite girders under positive moment. Journal of Structural Engineering, ASCE, 116(11):2931-2950, 1990.

[24] Chen S. and Gu P. Load carrying capacity of composite beams prestressed with external tendons under positive moment. Journal of Constructional Steel Research, 61(4):510-530, 2005.

[25] Saito D. and Wadee M. A. Post-buckling behaviour of prestressed steel stayed columns. Engineering Structures, 30:1224-1239, 2008. 
[26] Saito D. and Wadee M. A. Buckling behaviour of prestressed steel stayed columns with imperfections and stress limitation. Engineering Structures, 31:1-15, 2009.

[27] Osofero A. I., Wadee M. A., and Gardner L. Experimental study of critical and post-buckling behaviour of prestressed stayed columns. Journal of Constructional Steel Research, 79:226-241, 2012.

[28] Saito D. and Wadee M. A. Optimal prestressing and configuration of stayed columns. Proceedings of the Institution of Civil Engineers-Structures and Buildings, 163:343-355, 2010.

[29] Wadee M. A., Gardner L., and Osofero A. I. Design of prestressed stayed columns. Journal of Constructional Steel Research, 80:82-90, 2013.

[30] Gosaye J., Gardner L., Wadee M. A., and Ellen M. E. Tensile performance of prestressed steel elements. Engineering Structures, 79:234-243, 2014.

[31] BS EN ISO 6892-1:2009. British Standard: Metallic materials - Tensile testing. Part 1: Method of test at ambient temperature. The Standards Policy and Strategy Committee, 2009.

[32] Wang J., Afshan S., Schillo N., Theofanous M., Feldmann M., and Gardner L. Material properties and local buckling behaviour of high strength steel rectangular and square hollow sections. Engineering Structures, 130:297-315, 2017.

[33] EN 1992-1-1. Eurocode 2: Design of concrete structures. Part 1-1: General rules and rules for buildings. European Committee for Standardization (CEN), 2004.

[34] ABAQUS. ABAQUS/Standard user's manual volume IIII and ABAQUS CAE manual. Version 6.14, Hibbitt and Karlsson and Sorensen Inc. ABAQUS. USA: Pawtucket, 2014.

[35] Tao Z., Wang Z., and Yu Q. Finite element modelling of concrete-filled steel stub columns under axial compression. Journal of Constructional Steel Research, 89:121-131, 2013.

[36] ACI 318-11. Building Code Requirements for Structural Concrete (ACI 318-11) and Commentary. American Concrete Institute, 2011.

[37] FIP. CEB-FIP Model Code 1990. London: Thomas Telford Ltd., 1993.

[38] Bažant Z. P. and Becq-Giraudon E. Statistical prediction of fracture parameters of concrete and implications for choice of testing standard. Cement and Concrete Research, 32(4):529-556, 2002.

[39] Wang J. and Gardner L. Flexural buckling of hot-finished high strength steel SHS and RHS columns. Journal of Structural Engineering, ASCE, 2017. Accepted. 
[40] Ellobody E., Young B., and Lam D. Behaviour of normal and high strength concrete-filled compact steel tube circular stub columns. Journal of Constructional Steel Research, 62(7):706-716, 2006.

[41] EN 1090-2:2008. Execution of steel structures and aluminium structures: Technical requirements for steel structures. European Committee for Standardization (CEN), 2008.

[42] Chan T. M. and Gardner L. Flexural buckling of elliptical hollow section columns. Journal of Structural Engineering, ASCE, 135(5):546-557, 2009.

[43] Beer H. and Schulz G. Bases théoriques des courbes européenes de flambement. Constr. Metallique, 3:37-57, 1970 .

[44] EN 1993-1-11. Eurocode 3: Design of steel structures. Part 1-1: Design of structures with tension components. European Committee for Standardization (CEN), 2006.

[45] Ayrton W. E. and Perry J. On struts. Engineering (London), 62:464-465, 1886.

[46] EN 1993-1-1. Eurocode 3: Design of steel structures. Part 1-1: General rules and rules for buildings. European Committee for Standardization (CEN), 2005.

[47] EN 1994-1-1. Eurocode 4: Design of composite steel and concrete structures. Part 1-1: General rules and rules for buildings. European Committee for Standardization (CEN), 2004. 


\section{Tables}

Table 1: Design parameters of prestressed specimens.

\begin{tabular}{lllll}
\hline Specimen & $\begin{array}{l}\text { Nominal length } \\
(\mathrm{m})\end{array}$ & No. of cables & $\begin{array}{l}\text { Grouted } \\
(\mathrm{Y} / \mathrm{N})\end{array}$ & $\begin{array}{l}\text { Target prestress } \\
(\mathrm{kN})\end{array}$ \\
\hline T460NGN & 2 & 0 & $\mathrm{~N}$ & $\mathrm{~N} / \mathrm{A}$ \\
T460NG0 & 2 & 1 & $\mathrm{~N}$ & $5\left(\mathrm{P}_{\mathrm{nom}}\right)$ \\
T460NG1 & 2 & 1 & $\mathrm{~N}$ & $95\left(0.5 \mathrm{P}_{\mathrm{opt}}\right)$ \\
T460NG2 & 2 & 1 & $\mathrm{~N}$ & $189\left(\mathrm{P}_{\mathrm{opt}}\right)$ \\
T460G1 & 2 & 1 & $\mathrm{Y}$ & $95\left(0.5 \mathrm{P}_{\mathrm{opt}}\right)$ \\
T460G2 & 2 & 1 & $\mathrm{Y}$ & $189\left(\mathrm{P}_{\mathrm{opt}}\right)$ \\
C460NG0 & 1 & $\mathrm{~N}$ & $5\left(\mathrm{P}_{\mathrm{nom}}\right)$ \\
C460NG2 & 1 & 1 & $\mathrm{~N}$ & $189\left(\mathrm{P}_{\mathrm{opt}}\right)$ \\
C460G0 & 1 & 1 & $\mathrm{Y}$ & $5\left(\mathrm{P}_{\mathrm{nom}}\right)$ \\
C460G1 & 1 & 1 & $\mathrm{Y}$ & $95\left(0.5 \mathrm{P}_{\mathrm{opt}}\right)$ \\
C460G2 & 1 & 1 & $\mathrm{Y}$ & $189\left(\mathrm{P}_{\mathrm{opt}}\right)$ \\
\hline T690NGN & 2 & $\mathrm{~N}$ & $\mathrm{~N} / \mathrm{A}$ \\
T690NG0 & 2 & 1 & $\mathrm{~N}$ & $5\left(\mathrm{P}_{\mathrm{nom}}\right)$ \\
T690NG1 & 2 & 0 & $\mathrm{~N}$ & $84\left(0.5 \mathrm{P}_{\mathrm{opt}}\right)$ \\
T690NG2 & 2 & 1 & $\mathrm{~N}$ & $167\left(\mathrm{P}_{\mathrm{opt}}\right)$ \\
T690G1 & 2 & 1 & $\mathrm{Y}$ & $84\left(0.5 \mathrm{P}_{\mathrm{opt}}\right)$ \\
T690G2 & 2 & 1 & $\mathrm{Y}$ & $167\left(\mathrm{P}_{\mathrm{opt}}\right)$ \\
C690NG0 & 1 & 1 & $\mathrm{~N}$ & $5\left(\mathrm{P}_{\mathrm{nom}}\right)$ \\
C690NG2 & 1 & 1 & $\mathrm{~N}$ & $167\left(\mathrm{P}_{\mathrm{opt}}\right)$ \\
C690G0 & 1 & 1 & $\mathrm{Y}$ & $5\left(\mathrm{P}_{\mathrm{nom}}\right)$ \\
C690G1 & 1 & 1 & $84\left(0.5 \mathrm{P}_{\mathrm{opt}}\right)$ \\
C690G2 & 1 & 1 & $167\left(\mathrm{P}_{\mathrm{opt}}\right)$ \\
\hline & & 1 &
\end{tabular}

Table 2: Measured material properties of tube and cable.

\begin{tabular}{llll}
\hline Component & $\mathrm{E}_{\mathrm{t}}$ or $\mathrm{E}_{\mathrm{c}}\left(\mathrm{N} / \mathrm{mm}^{2}\right)$ & $\mathrm{f}_{\mathrm{ty}}$ or $\mathrm{f}_{\mathrm{cy}}\left(\mathrm{N} / \mathrm{mm}^{2}\right)$ & $\mathrm{A}_{\mathrm{t}}$ or $\mathrm{A}_{\mathrm{c}}\left(\mathrm{mm}^{2}\right)$ \\
\hline S460 SHS $50 \times 50 \times 5$ & 210000 & 505 & 858 \\
S690 SHS $50 \times 50 \times 5$ & 208000 & 759 & 841 \\
Cable & 130000 & 1703 & 151 \\
\hline
\end{tabular}

Table 3: Evolution of cube strength of grout with time.

\begin{tabular}{lllll}
\hline & Day 3 & Day 7 & Day 14 & Day 28 \\
\hline Cube strength, $\mathrm{f}_{\mathrm{gu}}\left(\mathrm{N} / \mathrm{mm}^{2}\right)$ & 40 & 46 & 52 & 57 \\
\hline
\end{tabular}


Table 4: Evolution of cube strength of grout with time for each specimen.

\begin{tabular}{|c|c|c|c|c|c|c|}
\hline Specimen & $\begin{array}{l}\text { Day } 1 \\
\mathrm{f}_{\mathrm{gu}, 1} \\
\left(\mathrm{~N} / \mathrm{mm}^{2}\right)\end{array}$ & $\begin{array}{l}\text { Day } 3 \\
\mathrm{f}_{\mathrm{gu}, 3} \\
\left(\mathrm{~N} / \mathrm{mm}^{2}\right)\end{array}$ & $\begin{array}{l}\text { Day } 7 \\
\mathrm{f}_{\mathrm{gu}, 7} \\
\left(\mathrm{~N} / \mathrm{mm}^{2}\right)\end{array}$ & $\begin{array}{l}\text { Test day } \\
\mathrm{f}_{\text {gu,test }} \\
\left(\mathrm{N} / \mathrm{mm}^{2}\right)\end{array}$ & $\begin{array}{l}\text { Day } 14 \\
\mathrm{f}_{\mathrm{gu}, 14} \\
\left(\mathrm{~N} / \mathrm{mm}^{2}\right)\end{array}$ & $\begin{array}{l}\text { Day } 28 \\
\mathrm{f}_{\mathrm{gu}, 28} \\
\left(\mathrm{~N} / \mathrm{mm}^{2}\right)\end{array}$ \\
\hline T460G1 & 32 & 39 & 45 & 47 & 47 & 54 \\
\hline T460G2 & 25 & 38 & 45 & 45 & 49 & - \\
\hline T690G1 & 30 & 36 & 41 & 43 & 45 & 47 \\
\hline T690G2 & 22 & 37 & 43 & 44 & 44 & 51 \\
\hline C460G0 \& C690G0 & 34 & 40 & 47 & 48 & 51 & - \\
\hline C460G1 \& C690G1 & 26 & 41 & 41 & 49 & 56 & - \\
\hline C460G2 \& C690G2 & 35 & 41 & 45 & 48 & 50 & 55 \\
\hline
\end{tabular}

Table 5: Measured dimensions and prestress levels of the tensile members.

\begin{tabular}{lllllll}
\hline Specimen & $\mathrm{L}_{0}(\mathrm{~mm})$ & $\mathrm{h}(\mathrm{mm})$ & $\mathrm{b}(\mathrm{mm})$ & $\mathrm{t}(\mathrm{mm})$ & $\mathrm{r}_{\text {ex }}(\mathrm{mm})$ & $\mathrm{P}_{\mathrm{i}}(\mathrm{kN})$ \\
\hline T460NGN & 1954 & 50.07 & 50.36 & 5.01 & 6.25 & $\mathrm{~N} / \mathrm{A}$ \\
T460NG0 & 1997 & 50.27 & 50.35 & 5.01 & 5.63 & $4.7\left(\mathrm{P}_{\text {nom }}\right)$ \\
T460NG1 & 2001 & 50.28 & 49.96 & 5.01 & 6.25 & $77.3\left(0.41 \mathrm{P}_{\text {opt }}\right)$ \\
T460NG2 & 2000 & 50.32 & 50.15 & 5.01 & 6.04 & $153.7\left(0.81 \mathrm{P}_{\text {opt }}\right)$ \\
T460G1 & 2002 & 50.11 & 50.25 & 5.01 & 5.75 & $84.0\left(0.44 \mathrm{P}_{\text {opt }}\right)$ \\
T460G2 & 2001 & 50.14 & 49.88 & 5.01 & 5.01 & $150.7\left(0.80 \mathrm{P}_{\text {opt }}\right)$ \\
T690NGN & 2000 & 50.18 & 50.43 & 4.91 & 5.88 & N/A \\
T690NG0 & 2000 & 50.27 & 50.37 & 4.91 & 5.88 & $5.7\left(\mathrm{P}_{\text {nom }}\right)$ \\
T690NG1 & 1999 & 50.11 & 50.36 & 4.91 & 5.88 & $65.0\left(0.36 \mathrm{P}_{\text {opt }}\right)$ \\
T690NG2 & 2003 & 50.50 & 50.12 & 4.91 & 5.88 & $131.0\left(0.78 \mathrm{P}_{\text {opt }}\right)$ \\
T690G1 & 2001 & 50.26 & 50.40 & 4.91 & 5.88 & $86.2\left(0.52 \mathrm{P}_{\text {opt }}\right)$ \\
T690G2 & 1954 & 50.38 & 50.28 & 4.91 & 5.88 & $124.3\left(0.74 \mathrm{P}_{\text {opt }}\right)$ \\
\hline
\end{tabular}

Table 6: Geometric properties and prestress levels of the compressive members.

\begin{tabular}{llllllll}
\hline Specimen & $\mathrm{L}_{0}(\mathrm{~mm})$ & $\mathrm{h}(\mathrm{mm})$ & $\mathrm{b}(\mathrm{mm})$ & $\mathrm{t}(\mathrm{mm})$ & $\mathrm{r}_{\mathrm{ex}}(\mathrm{mm})$ & $\omega_{\mathrm{i}}+\mathrm{e}_{\mathrm{i}}(\mathrm{mm})$ & $\mathrm{P}_{\mathrm{i}}(\mathrm{kN})$ \\
\hline C460NG0 & 1003 & 50.32 & 50.19 & 5.01 & 5.97 & 1.28 & $6.8\left(\mathrm{P}_{\text {nom }}\right)$ \\
C460NG2 & 1002 & 50.11 & 50.31 & 5.01 & 5.97 & 1.58 & $125.6\left(0.67 \mathrm{P}_{\text {opt }}\right)$ \\
C460G0 & 1001 & 50.13 & 50.42 & 5.01 & 5.97 & 0.92 & $7.1\left(\mathrm{P}_{\text {nom }}\right)$ \\
C460G1 & 1002 & 50.36 & 50.10 & 5.01 & 5.97 & 2.41 & $70.8\left(0.37 \mathrm{P}_{\text {opt }}\right)$ \\
C460G2 & 1002 & 50.11 & 50.40 & 5.01 & 5.97 & 1.56 & $152.7\left(0.81 \mathrm{P}_{\text {opt }}\right)$ \\
C690NG0 & 1000 & 50.42 & 50.14 & 4.91 & 5.88 & 0.82 & $3.7\left(\mathrm{P}_{\text {nom }}\right)$ \\
C690NG2 & 1000 & 50.38 & 50.20 & 4.91 & 5.88 & 0.81 & $120.8\left(0.72 \mathrm{P}_{\text {opt }}\right)$ \\
C690G0 & 1000 & 50.11 & 50.35 & 4.91 & 5.88 & 0.44 & $5.0\left(\mathrm{P}_{\text {nom }}\right)$ \\
C690G1 & 1002 & 50.14 & 50.39 & 4.91 & 5.88 & 1.42 & $65.2\left(0.39 \mathrm{P}_{\text {opt }}\right)$ \\
C690G2 & 1001 & 50.26 & 50.26 & 4.91 & 5.88 & 0.09 & $123.5\left(0.74 \mathrm{P}_{\text {opt}}\right)$ \\
\hline
\end{tabular}


Table 7: Summary of tensile member test results.

\begin{tabular}{lllllll}
\hline Specimen & $\mathrm{k}(\mathrm{kN} / \mathrm{mm})$ & $\mathrm{N}_{\mathrm{y}}(\mathrm{kN})$ & $\delta_{\mathrm{y}}(\mathrm{mm})$ & $\mathrm{N}_{\mathrm{u}}(\mathrm{kN})$ & $\delta_{\mathrm{u}}(\mathrm{mm})$ & $\mathrm{N}_{\mathrm{uc}}(\mathrm{kN})$ \\
\hline T460NGN & 81.6 & 393.9 & 5.2 & 524.0 & 198.4 & $\mathrm{~N} / \mathrm{A}$ \\
T460NG0 & 91.9 & 431.6 & 5.3 & 669.0 & 36.1 & 259.4 \\
T460NG1 & 90.4 & 548.9 & 6.5 & 717.7 & 53.9 & 275.6 \\
T460NG2 & 93.2 & 631.0 & 7.6 & 661.9 & 17.1 & 261.3 \\
T460G1 & 98.4 & 561.7 & 6.4 & 817.1 & 126.8 & - \\
T460G2 & 96.5 & 635.7 & 7.2 & 812.1 & 118.5 & - \\
T690NGN & 84.2 & 679.6 & 8.4 & 726.8 & 100.3 & N/A \\
T690NG0 & 91.3 & 719.2 & 8.3 & 946.8 & 35.6 & 257.9 \\
T690NG1 & 97.8 & 847.7 & 10.4 & 970.6 & 60.5 & 278.4 \\
T690NG2 & 90.9 & 898.9 & 10.6 & 942.1 & 24.9 & 268.5 \\
T690G1 & 99.3 & 827.2 & 8.7 & 1019.3 & 102.4 & - \\
T690G2 & 100.2 & 901.2 & 9.8 & 1017.5 & 89.3 & - \\
\hline
\end{tabular}

Table 8: Summary of compressive member test results.

\begin{tabular}{lll}
\hline Specimen & $\mathrm{P}_{\mathrm{i}}(\mathrm{kN})$ & $\mathrm{N}_{\mathrm{u}}(\mathrm{kN})$ \\
\hline C460NG0 & 6.8 & 280.4 \\
C460NG2 & 125.6 & 232.2 \\
C460G0 & 7.1 & 294.5 \\
C460G1 & 70.8 & 255.1 \\
C460G2 & 152.7 & 243.8 \\
C690NG0 & 3.7 & 329.3 \\
C690NG2 & 120.8 & 322.0 \\
C690G0 & 5.0 & 386.0 \\
C690G1 & 65.2 & 342.9 \\
C690G2 & 123.5 & 419.9 \\
\hline
\end{tabular}


Table 9: Comparison of ultimate experimental and numerical capacities for compressive members.

\begin{tabular}{llll}
\hline Specimen & $\mathrm{N}_{\mathrm{u}, \text { test }}(\mathrm{kN})$ & $\mathrm{N}_{\mathrm{u}, \mathrm{FE}}(\mathrm{kN})$ & $\mathrm{N}_{\mathrm{u}, \mathrm{FE}} / \mathrm{N}_{\mathrm{u}, \text { test }}$ \\
\hline C460NG0 & 280.4 & 274.5 & 0.98 \\
C460NG2 & 232.2 & 228.0 & 0.98 \\
C460G0 & 294.5 & 308.3 & 1.05 \\
C460G1 & 255.1 & 257.5 & 1.01 \\
C460G2 & 243.8 & 247.2 & 1.01 \\
C690NG0 & 329.3 & 318.4 & 0.97 \\
C690NG2 & 322.0 & 310.2 & 0.96 \\
C690G0 & 386.0 & 337.1 & 0.87 \\
C690G1 & 342.9 & 321.0 & 0.94 \\
C690G2 & 419.9 & 351.5 & 0.84 \\
\hline Mean & & & 0.96 \\
COV & & & 0.067 \\
\hline
\end{tabular}

Table 10: Summary of comparisons between predicted tensile capacities and test results.

\begin{tabular}{llll}
\hline Specimen & $\mathrm{N}_{\mathrm{y}, \text { test }}(\mathrm{kN})$ & $\mathrm{N}_{\mathrm{t}, \mathrm{Rd}}(\mathrm{kN})$ & $\mathrm{N}_{\mathrm{y}, \text { test }} / \mathrm{N}_{\mathrm{t}, \mathrm{Rd}}$ \\
\hline T460NG0 & 442.5 & 497.0 & 0.89 \\
T460NG1 & 548.9 & 572.5 & 0.96 \\
T460NG2 & 631.0 & 659.2 & 0.96 \\
T460G1 & 561.7 & 582.6 & 0.96 \\
T460G2 & 635.7 & 654.4 & 0.97 \\
T690NG0 & 719.2 & 732.4 & 0.98 \\
T690NG1 & 847.7 & 796.9 & 1.06 \\
T690NG2 & 898.9 & 871.1 & 1.03 \\
T690G1 & 827.2 & 821.8 & 1.01 \\
T690G2 & 901.2 & 864.1 & 1.04 \\
\hline Mean & & & 0.99 \\
COV & & & 0.051 \\
\hline
\end{tabular}

Table 11: Comparison between design capacity predictions and test and FE results for compression members.

\begin{tabular}{llll}
\hline Dataset & No. of test/FE results & \multicolumn{2}{c}{$\mathrm{N}_{\mathrm{u}, \text { test }} / \mathrm{N}_{\mathrm{b}, \mathrm{Rd}}$ or $\mathrm{N}_{\mathrm{u}, \mathrm{FE}} / \mathrm{N}_{\mathrm{b}, \mathrm{Rd}}$} \\
\cline { 3 - 4 } & & Mean & $\mathrm{COV}$ \\
\hline S460 test & 5 & 0.99 & 0.046 \\
S460 test+FE & 101 & 1.03 & 0.050 \\
S690 test & 3 & 1.06 & 0.012 \\
S690 test+FE & 99 & 1.05 & 0.033 \\
S235 test [1] & 8 & 1.02 & 0.053 \\
S235 test+FE [1] & 32 & 1.07 & 0.093 \\
\hline
\end{tabular}




\section{Figures}

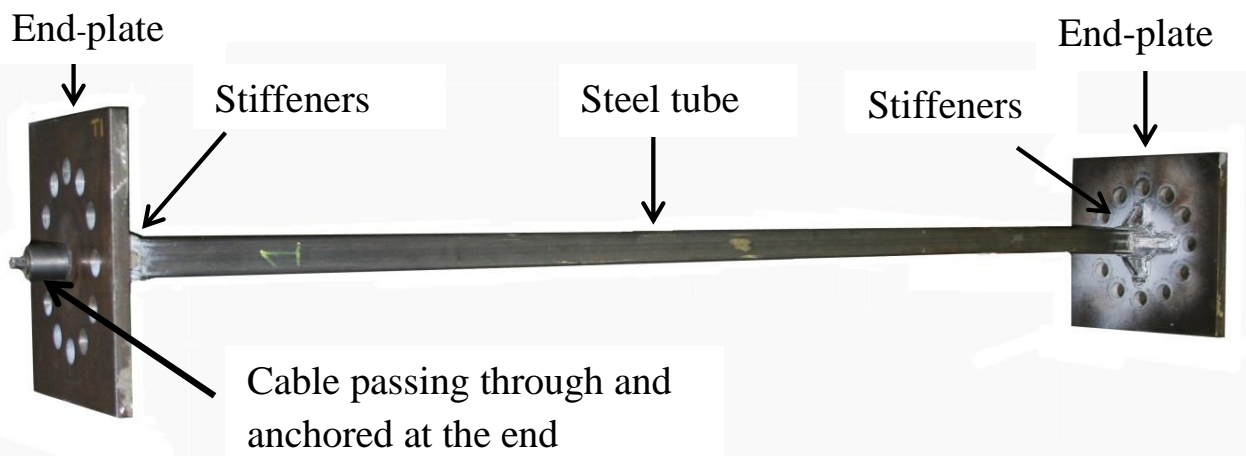

Figure 1: Typical configuration of tested specimens.

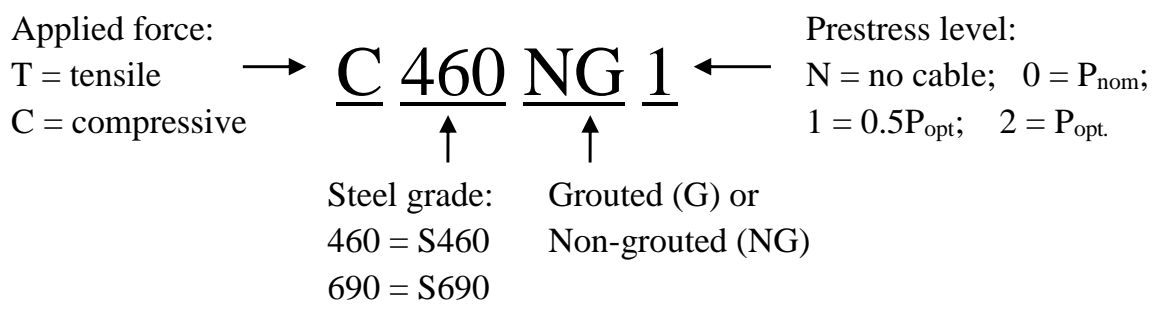

Figure 2: Labelling system of tested specimens.

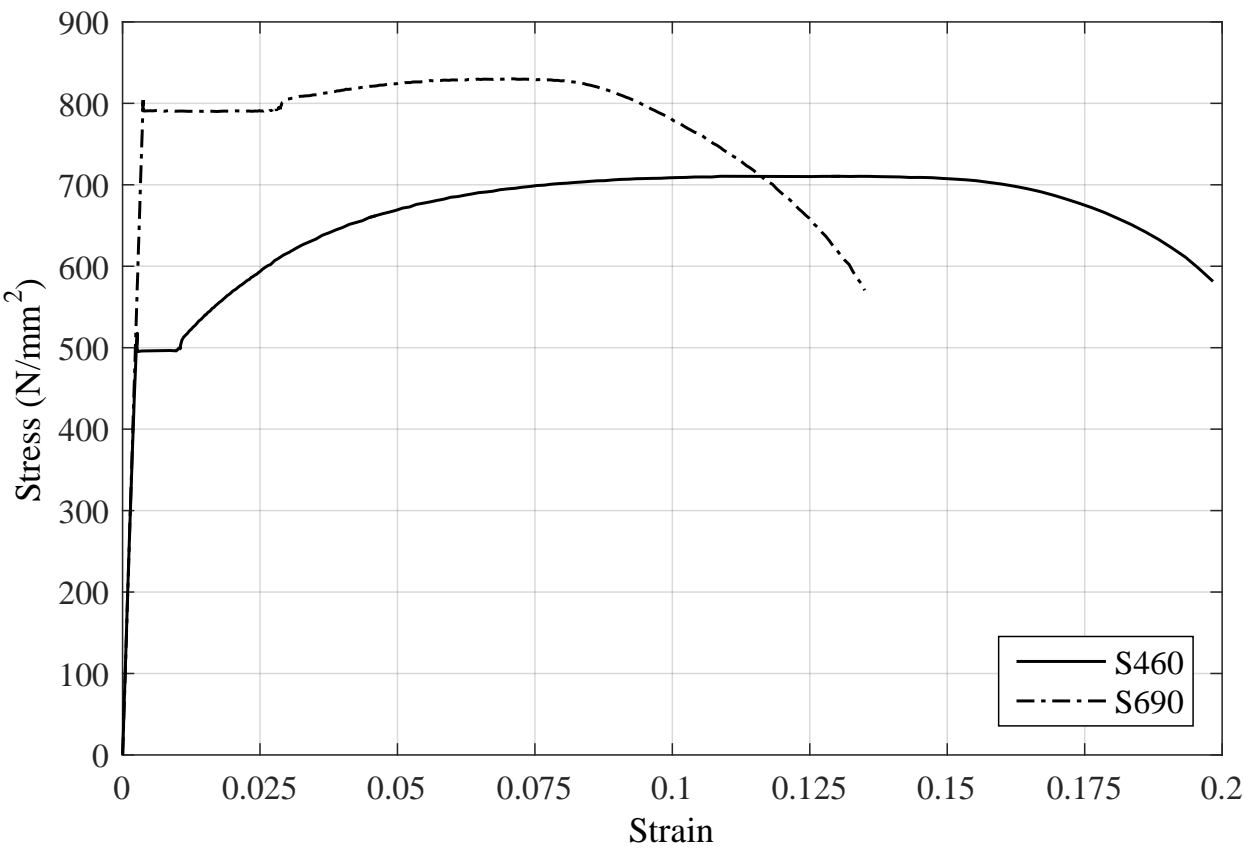

Figure 3: Measured stress-strain curves from S460 and S690 tensile flat coupon tests. 


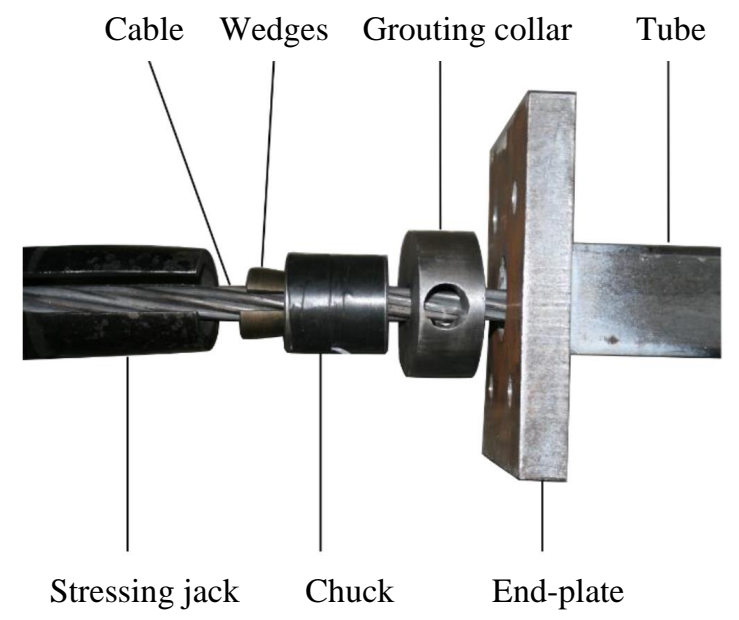

Figure 4: Components of prestressing and anchoring systems.

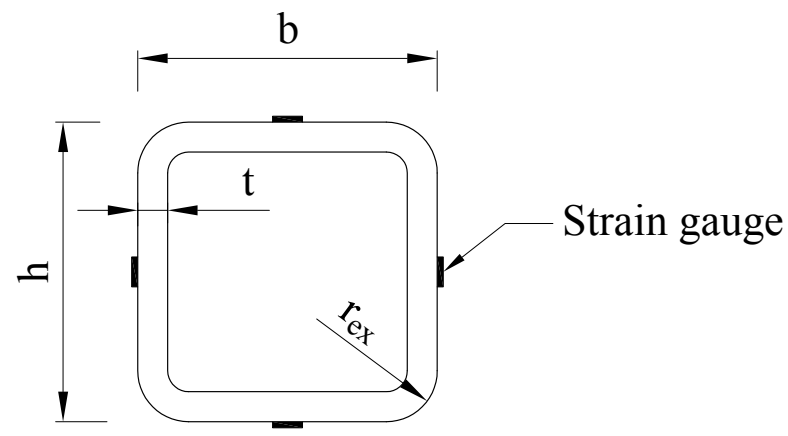

Figure 5: Definitions of cross-section symbols and locations of strain gauges.

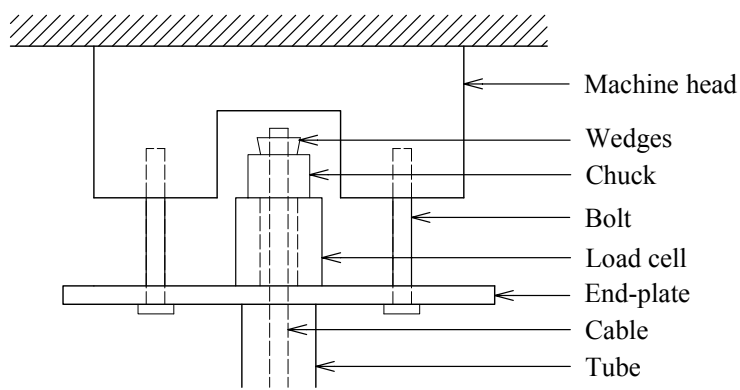

(a) Non-grouted members

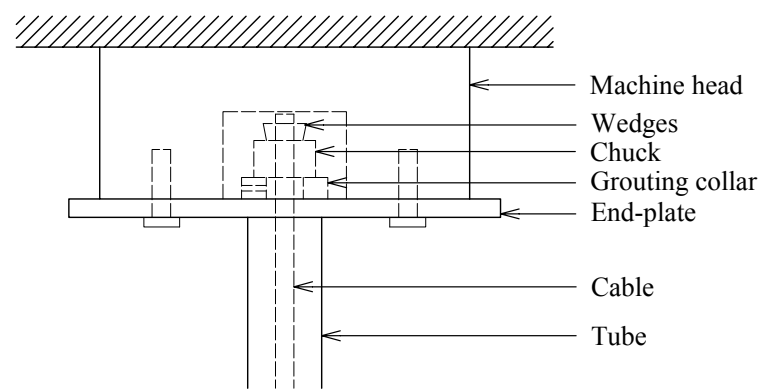

(b) Grouted members

Figure 6: End-plate bolting arrangement for tensile member tests. 


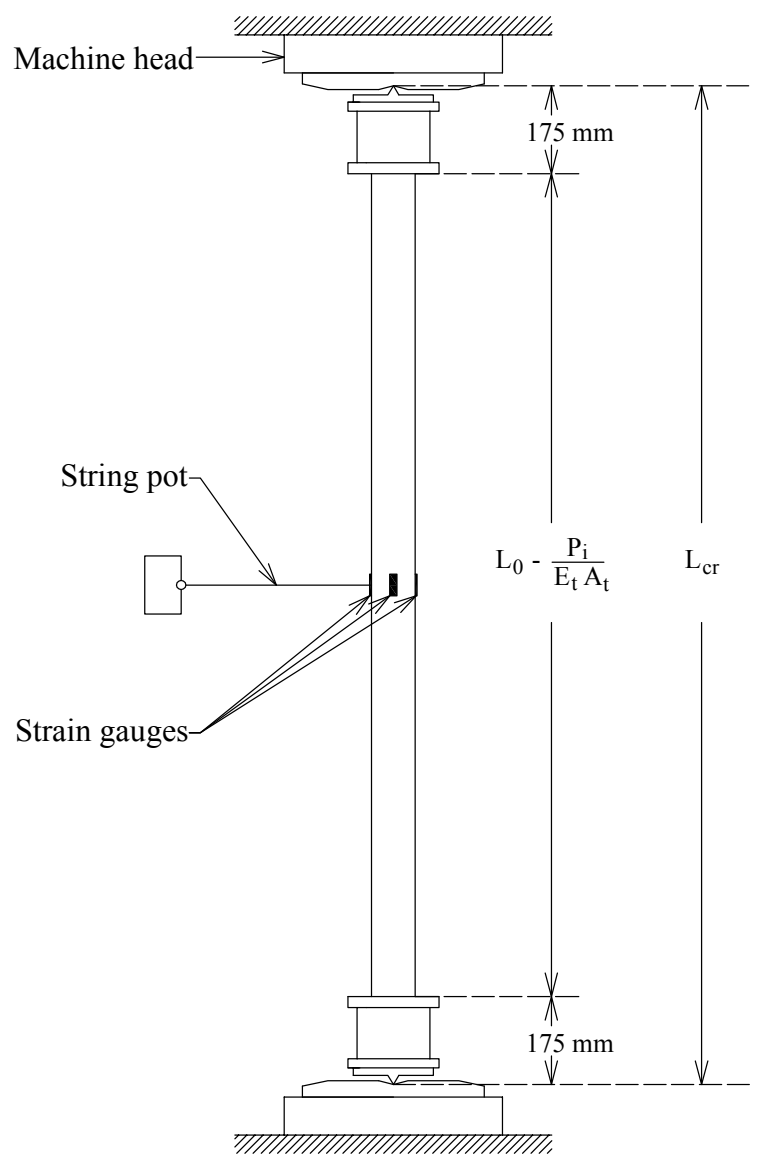

(a) Schematic view of test set-up

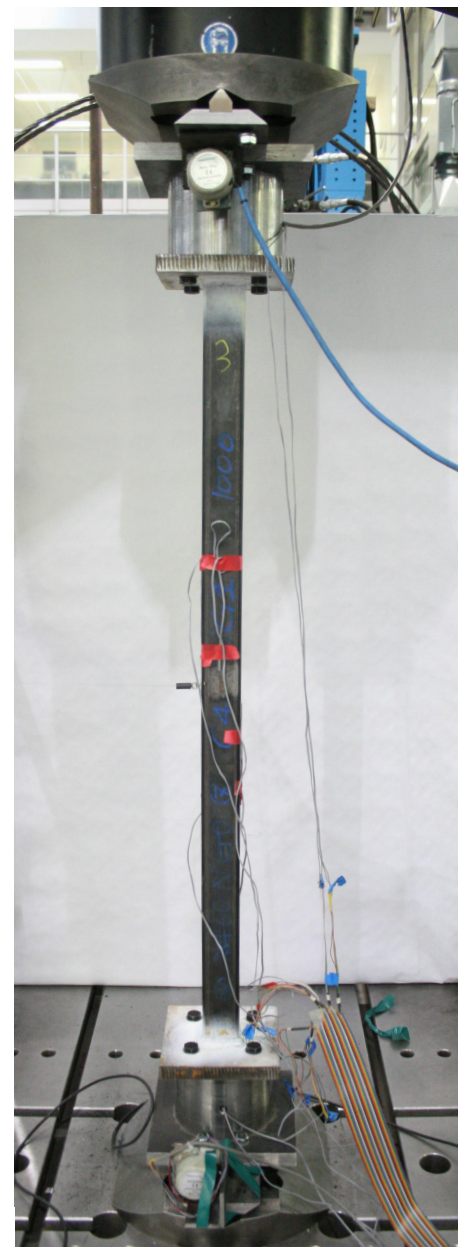

(b) Photo of test set-up

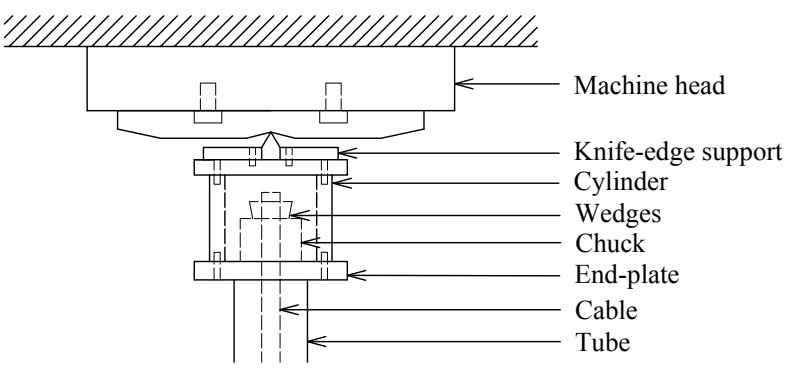

(c) Knife-edge detail for non-grouted members

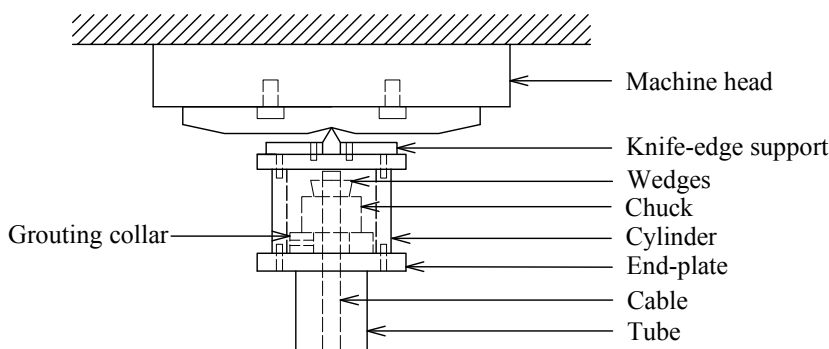

(d) Knife-edge detail for grouted members

Figure 7: Set-up and end details for compressive member tests. 


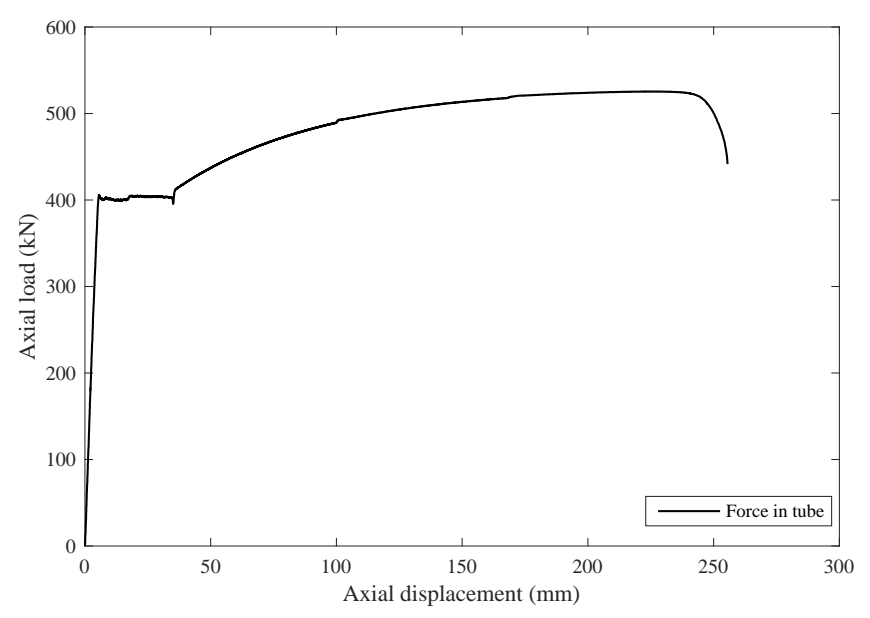

(a) T460NGN

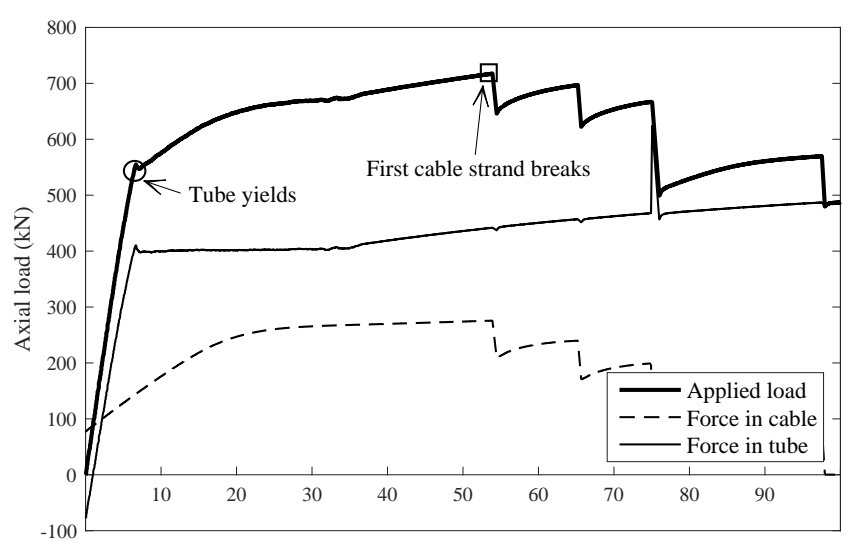

Axial displacement (mm)

(c) T460NG1

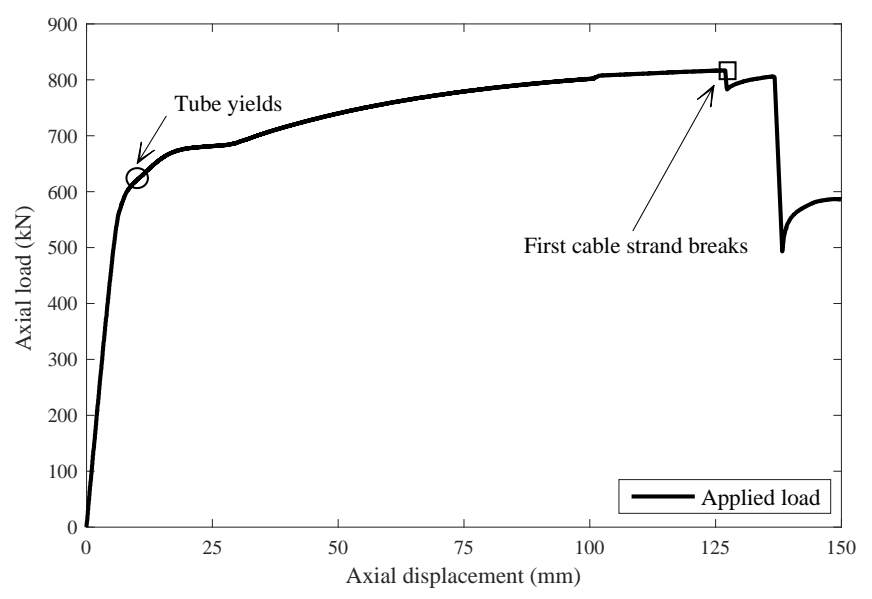

(e) T460G1

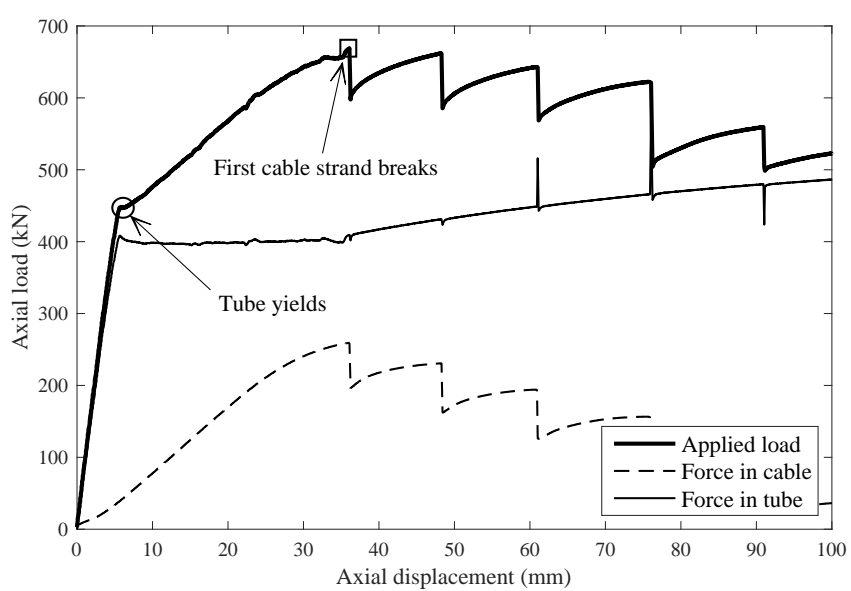

(b) T460NG0

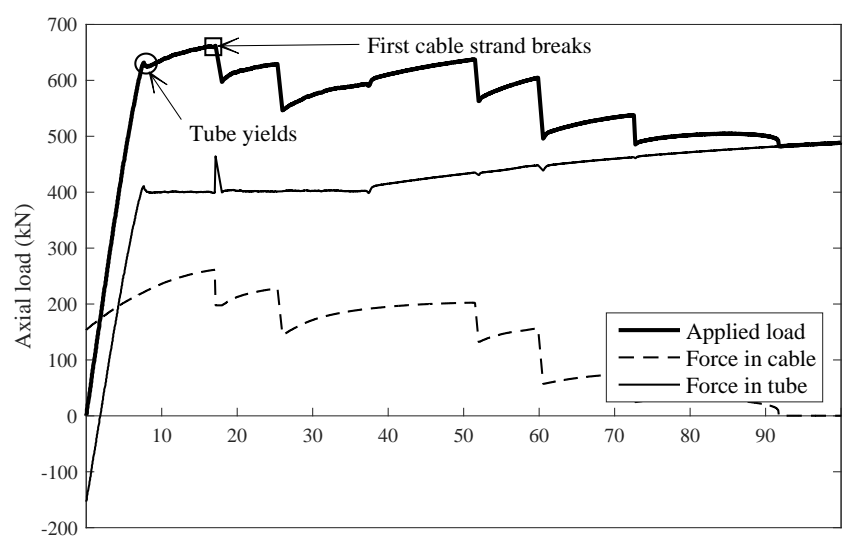

Axial displacement (mm)

(d) T460NG2

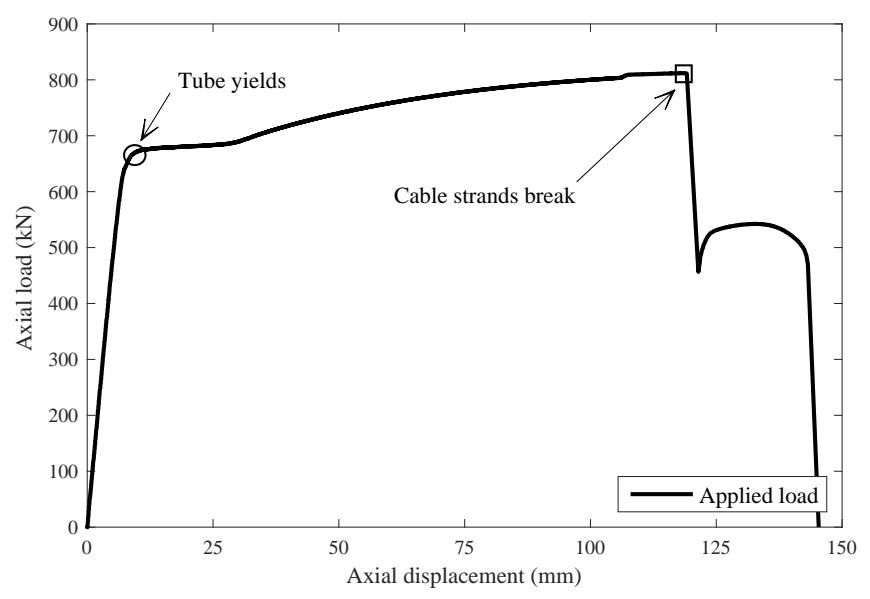

(f) T460G2

Figure 8: Measured load-axial displacement curves for the S460 tensile specimens. 


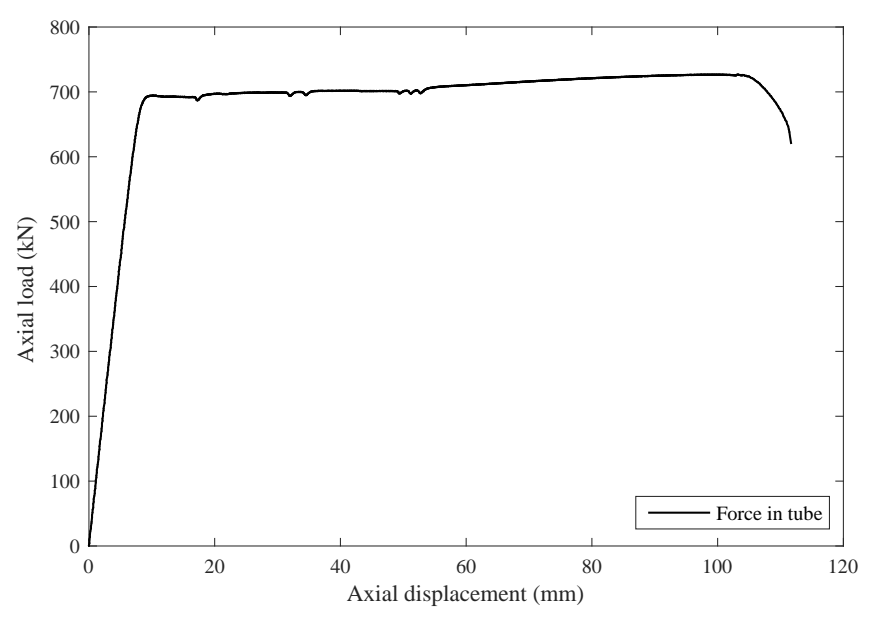

(a) T690NGN

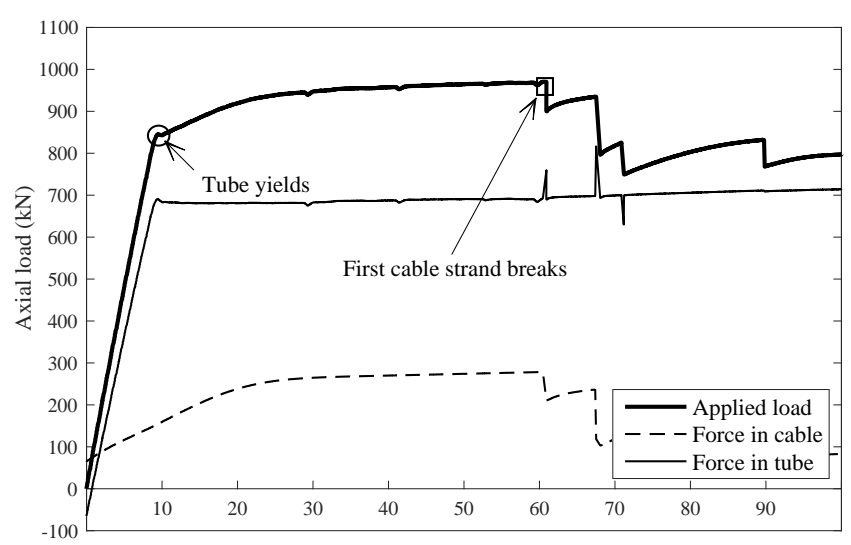

Axial displacement (mm)

(c) T690NG1

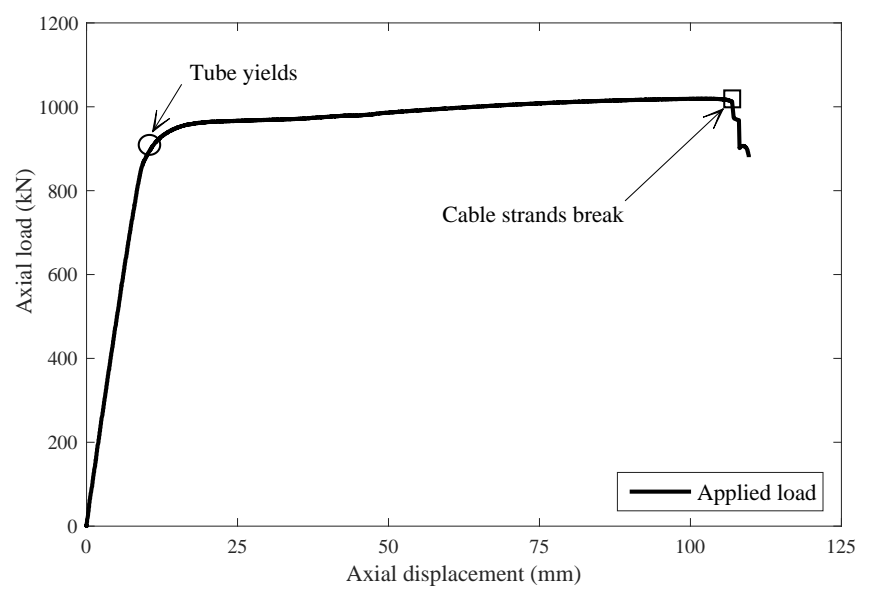

(e) T690G1

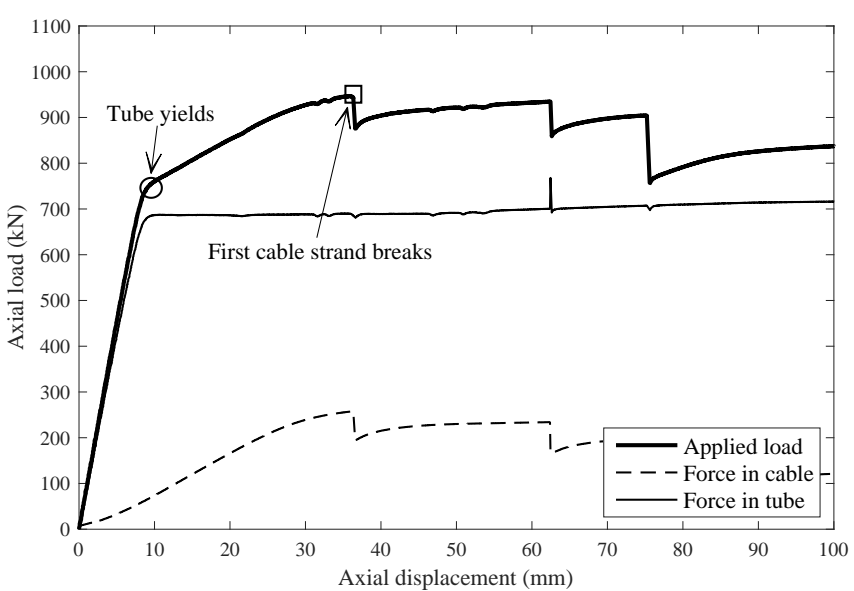

(b) T690NG0

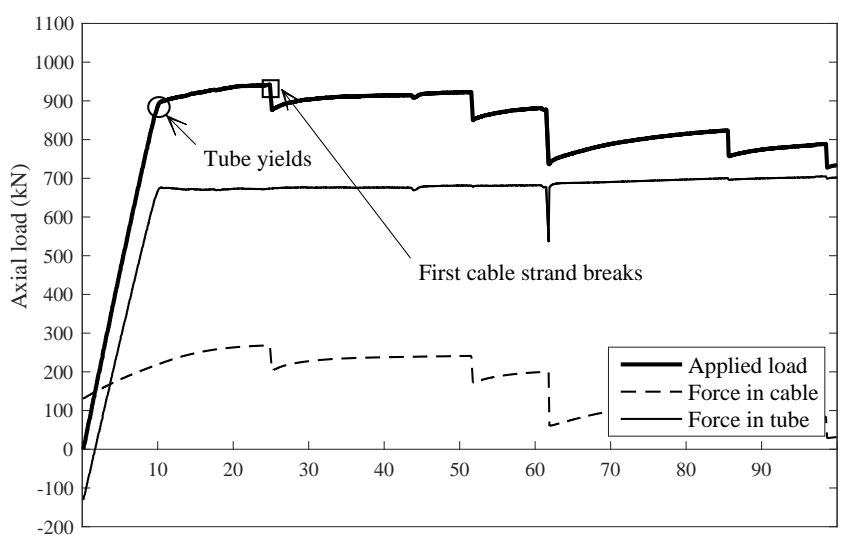

Axial displacement (mm)

(d) T690NG2

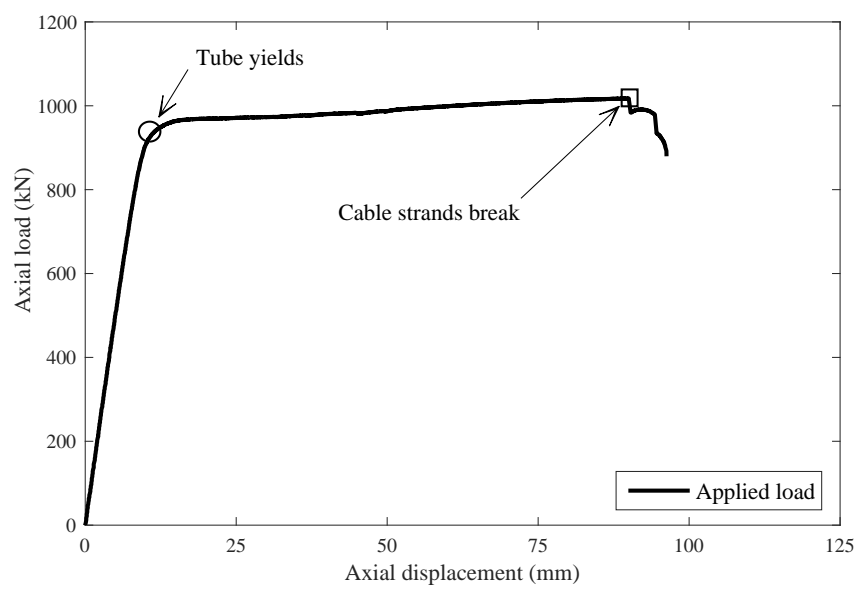

(f) T690G2

Figure 9: Measured load-axial displacement curves for the S690 tensile specimens. 


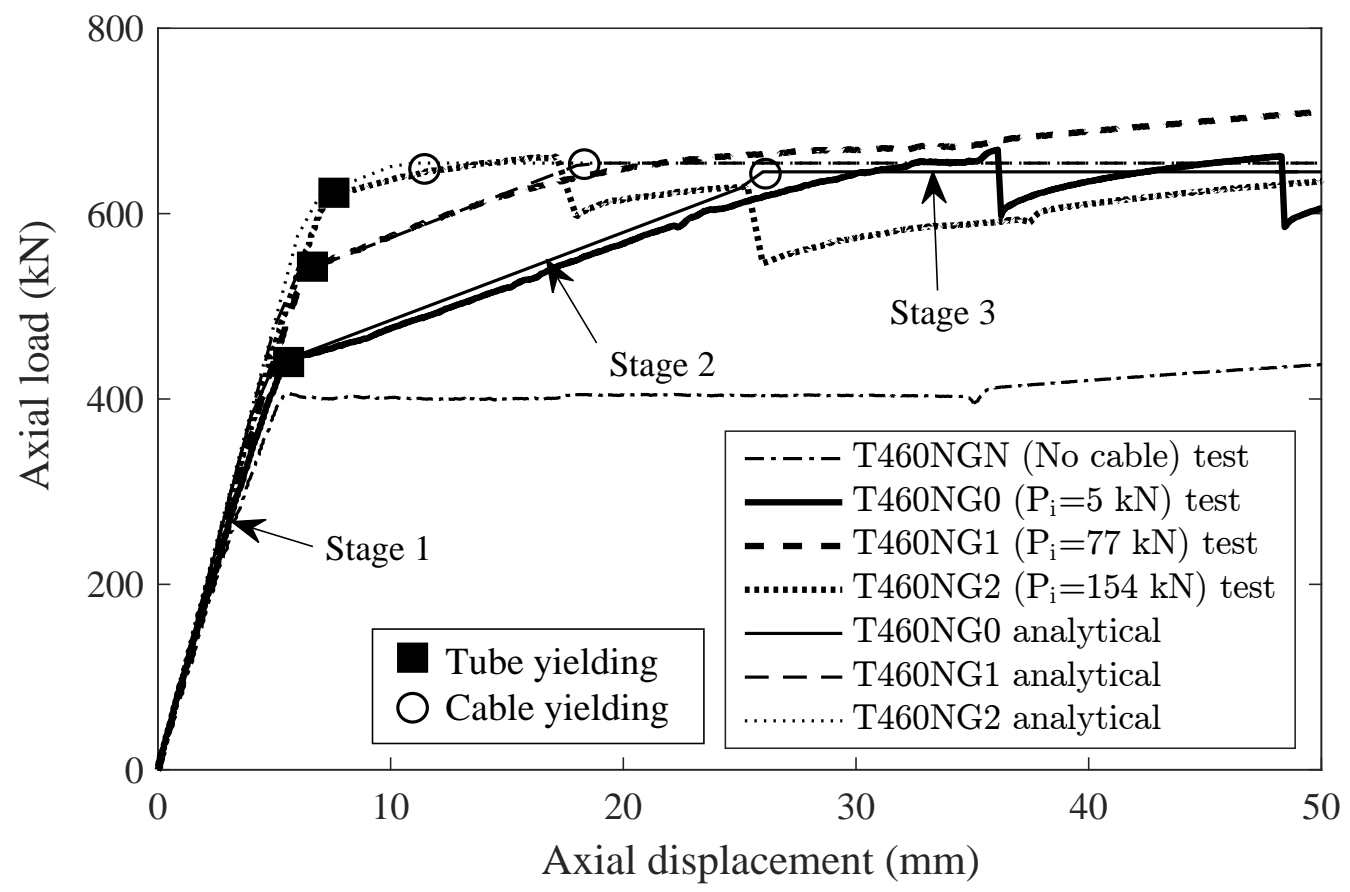

(a) S460 members

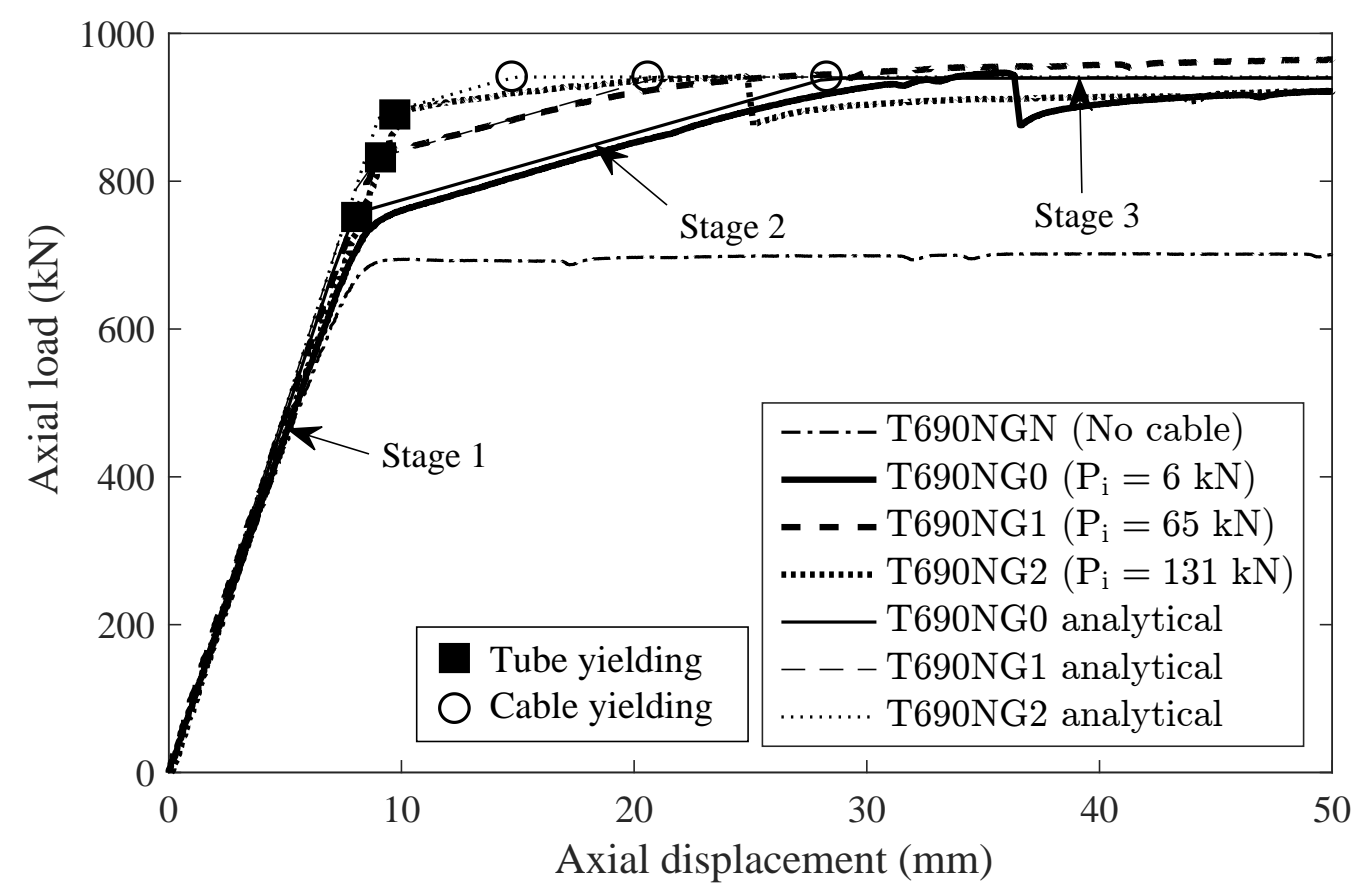

(b) S690 members

Figure 10: Comparisons of the experimental and analytical load-axial displacement curves for non-grouted tensile specimens. 


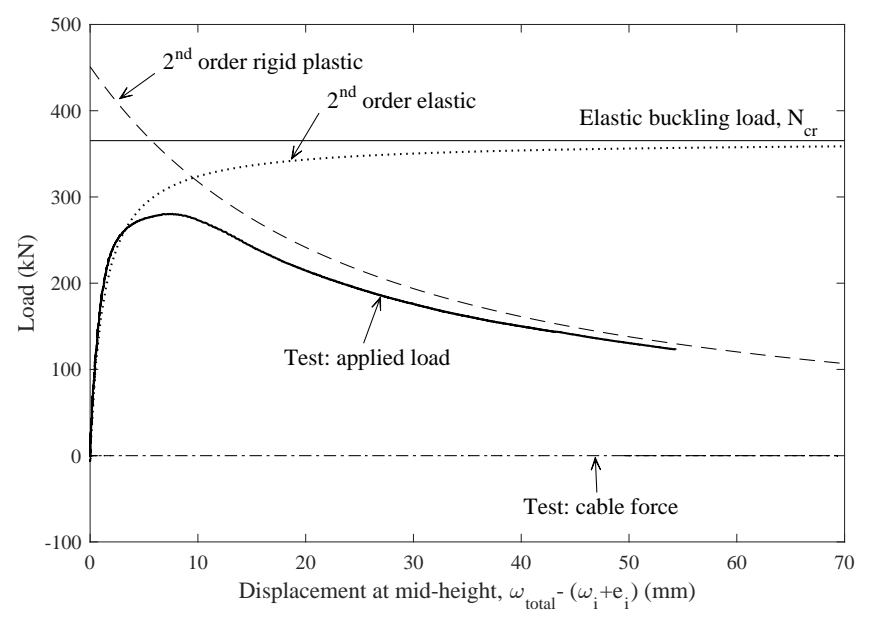

(a) $\mathrm{C} 460 \mathrm{NG} 0$

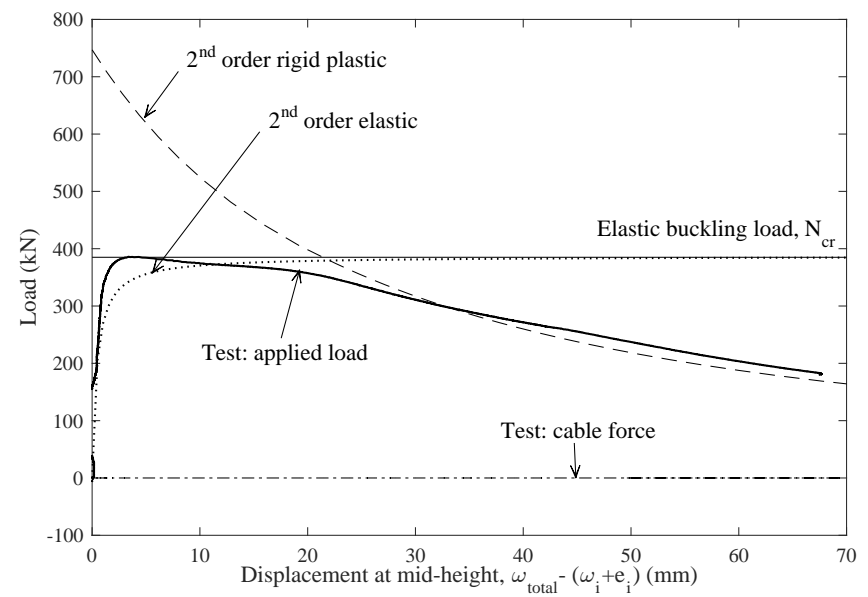

(c) C690G0

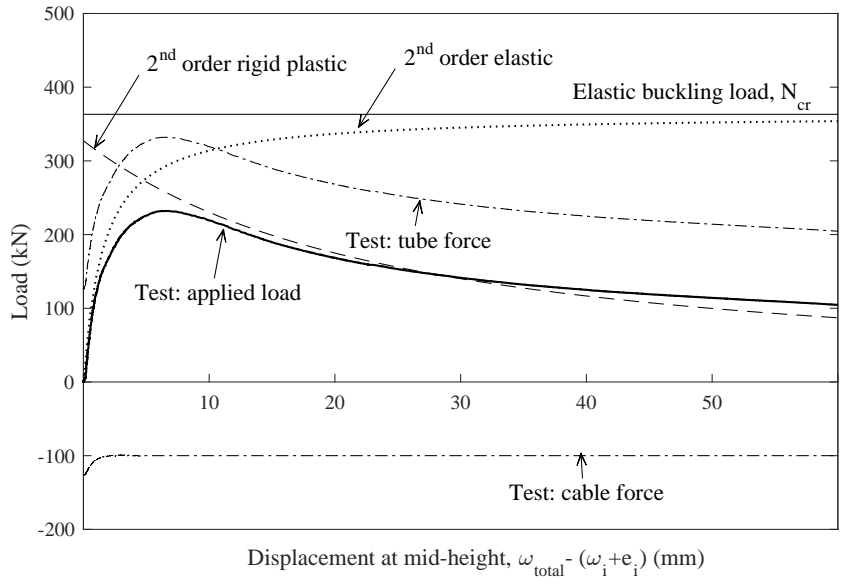

(b) C460NG2

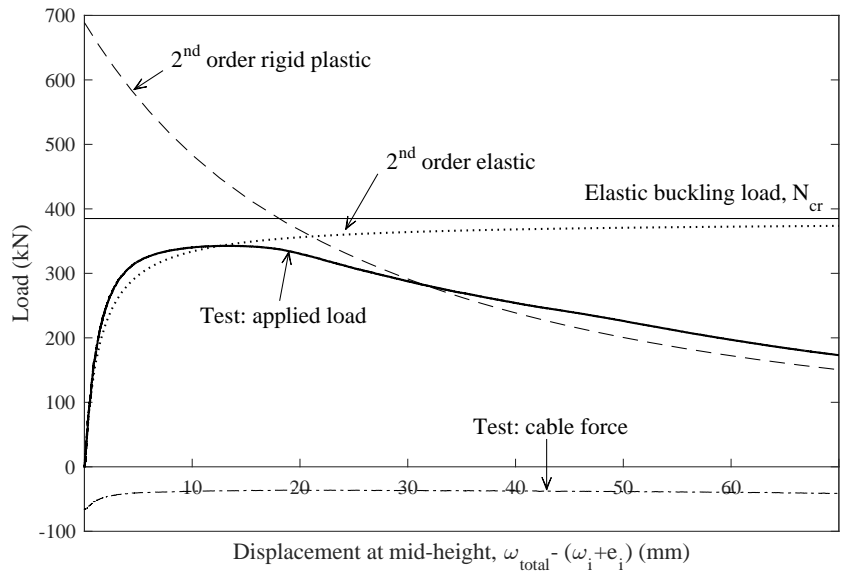

(d) C690G1

Figure 11: Comparison between load-lateral deflection curves and analytical models for the S460 and S690 compressive specimens.

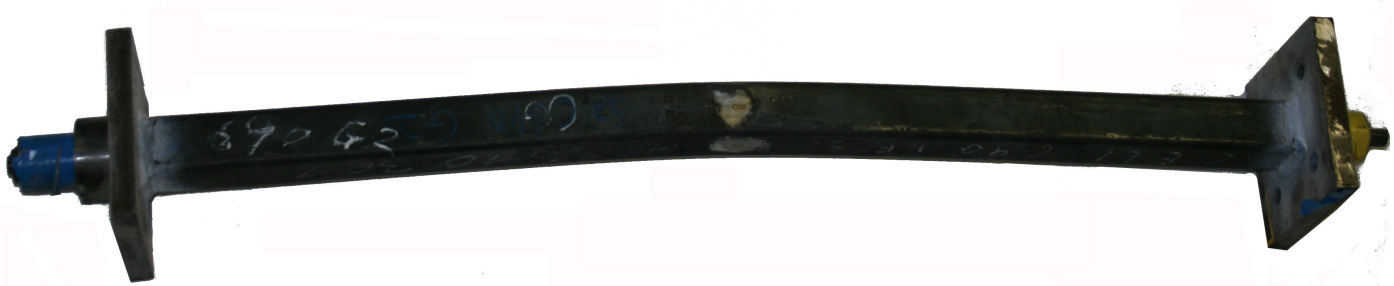

Figure 12: Typical failure mode from the tested compression members. 


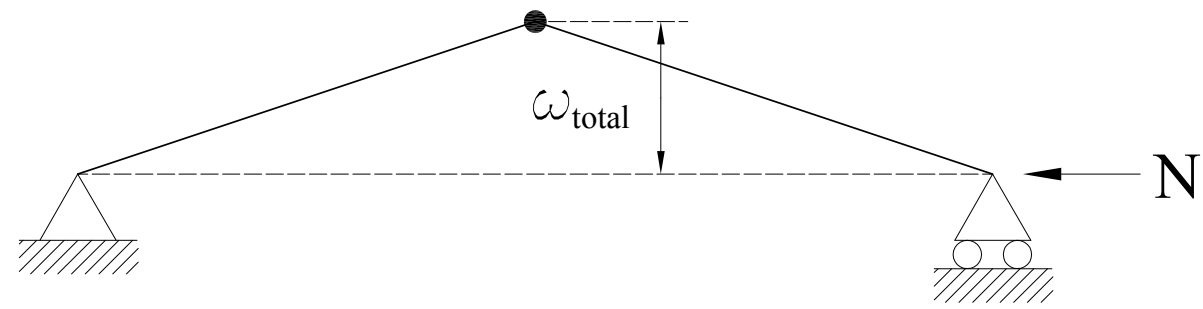

Figure 13: Second order rigid plastic model.

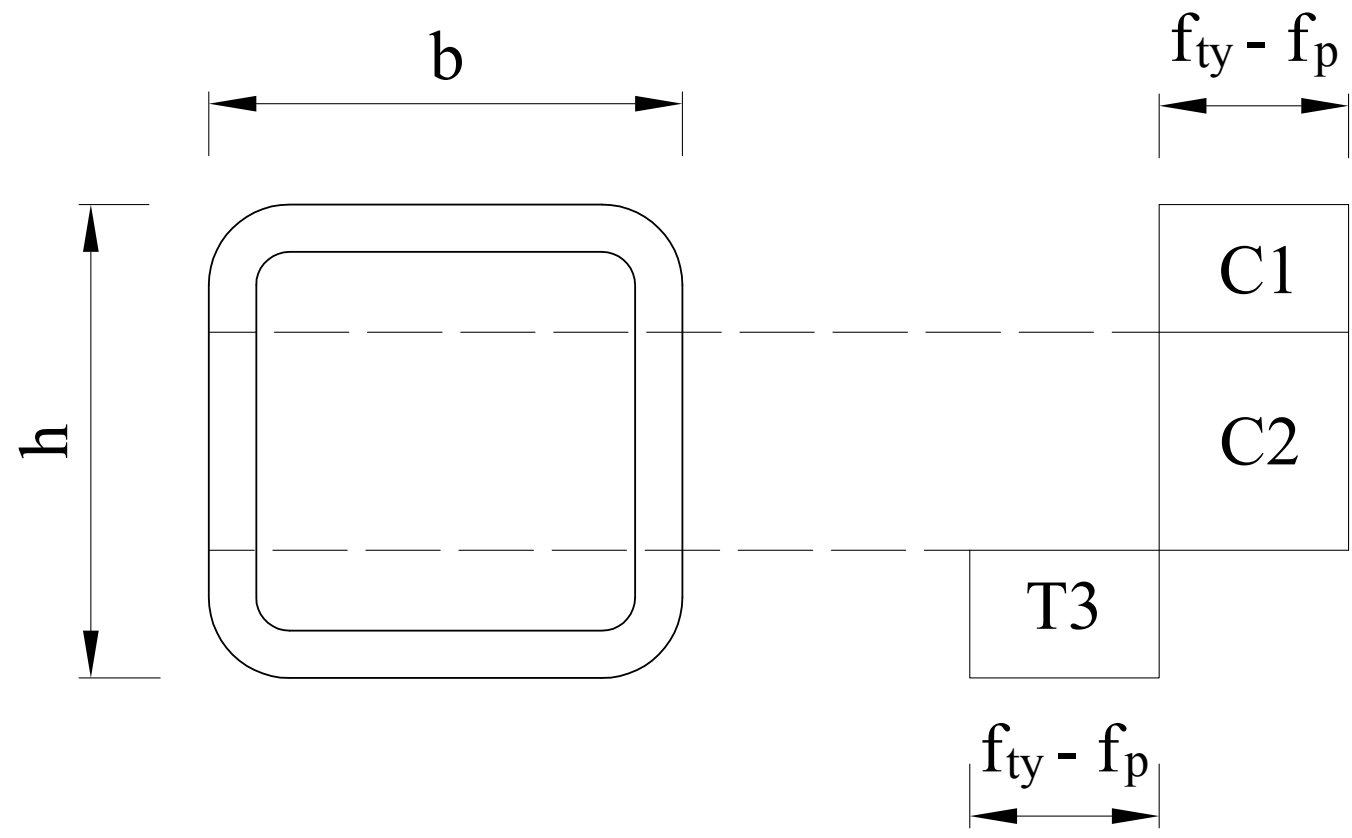

Figure 14: Plastic stress distribution associated with second order rigid plastic model.

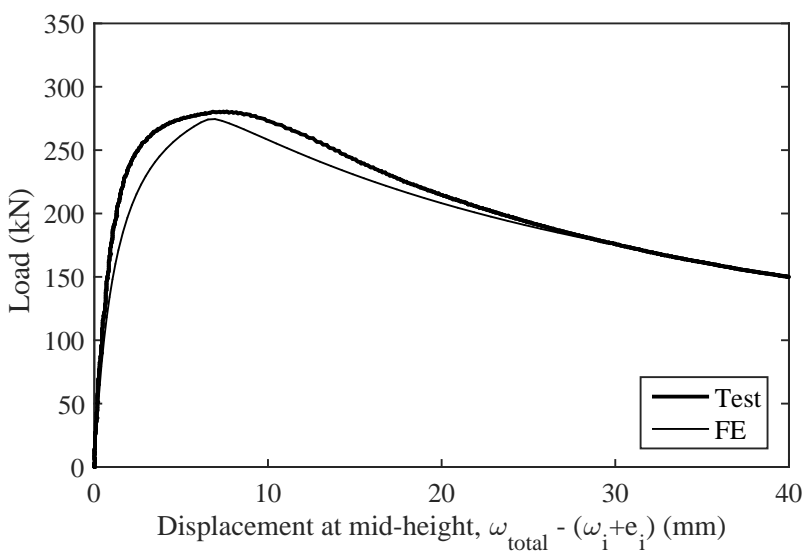

(a) C460NG0

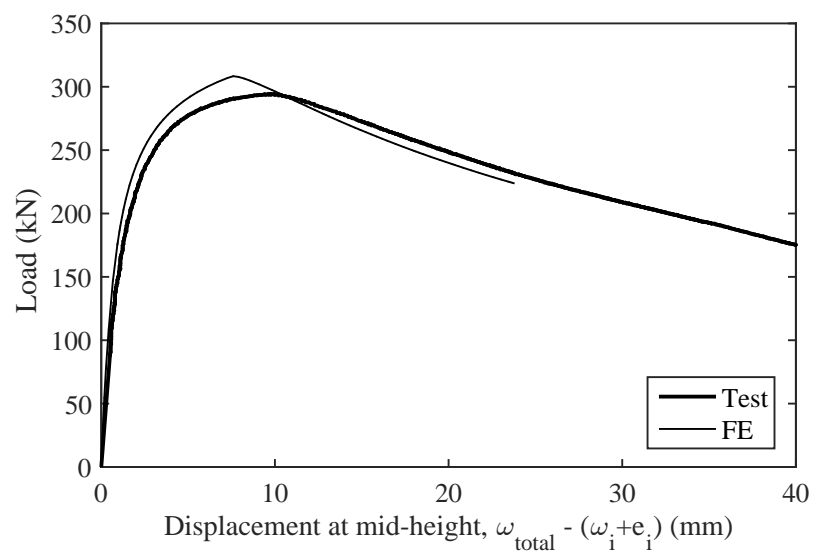

(b) C460G0

Figure 15: Comparison between the load-lateral displacement curves obtained from the test and FE models. 


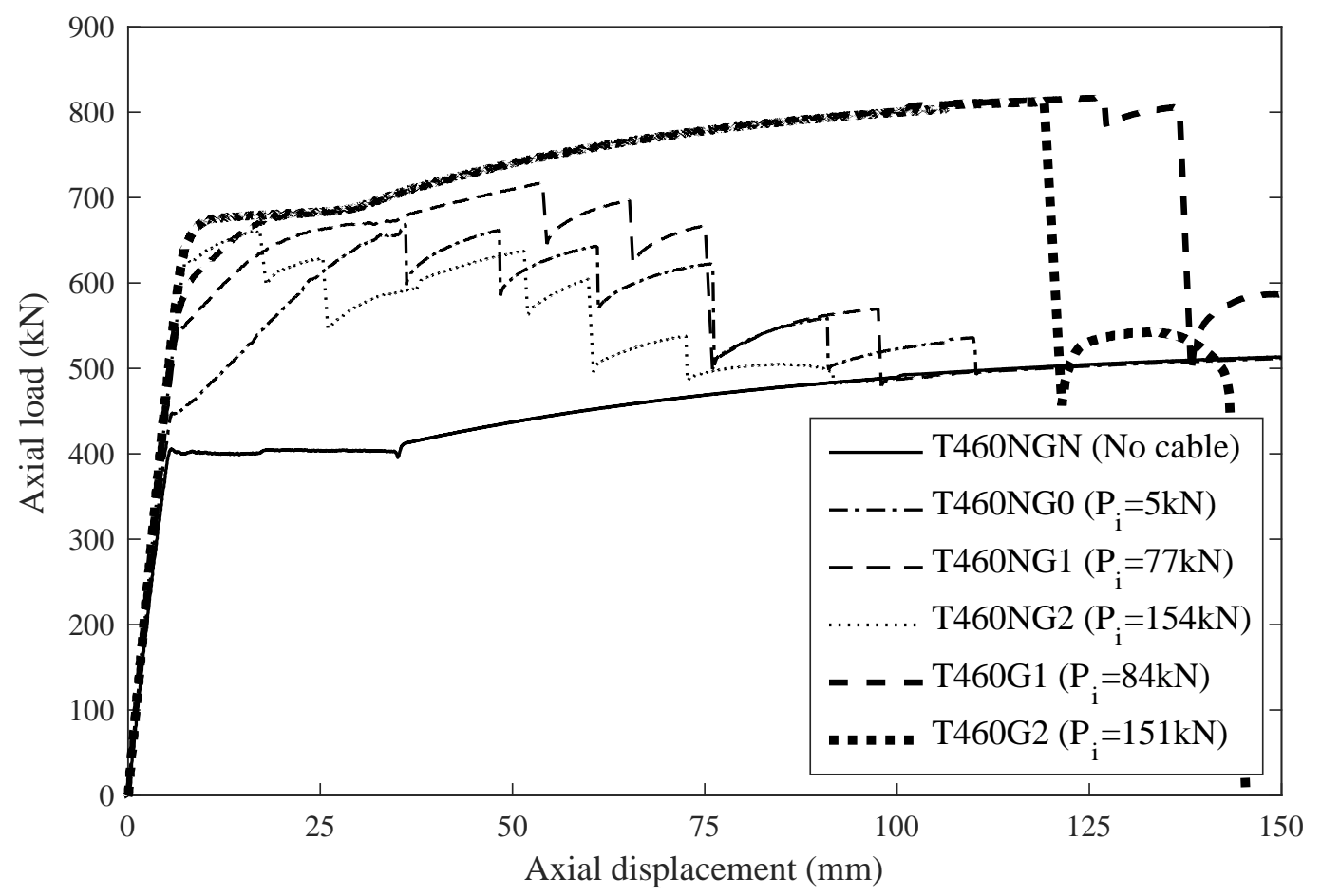

Figure 16: Comparison of the overall tensile load-displacement responses of S460 specimens.

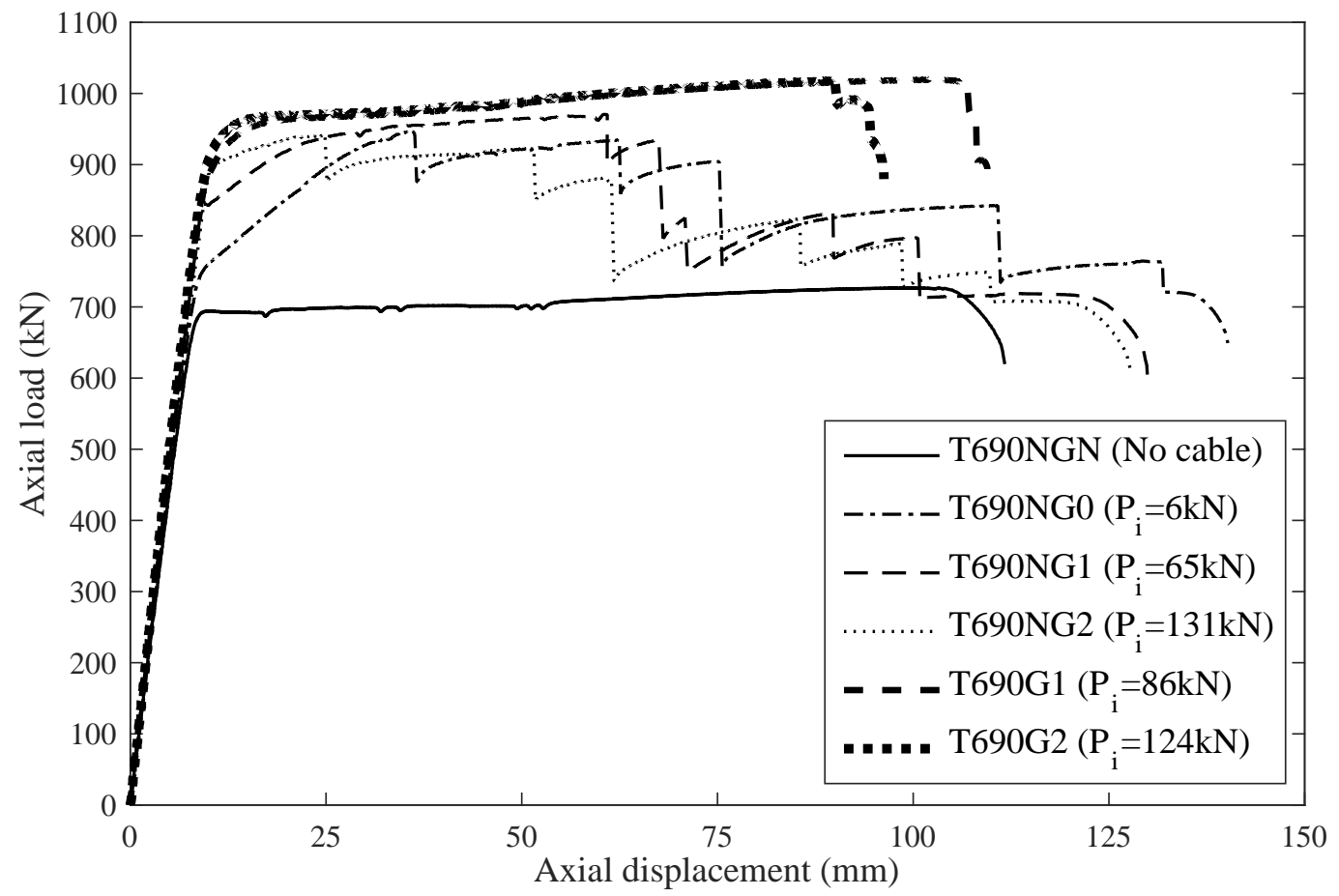

Figure 17: Comparison of the overall tensile load-displacement responses of S690 specimens. 


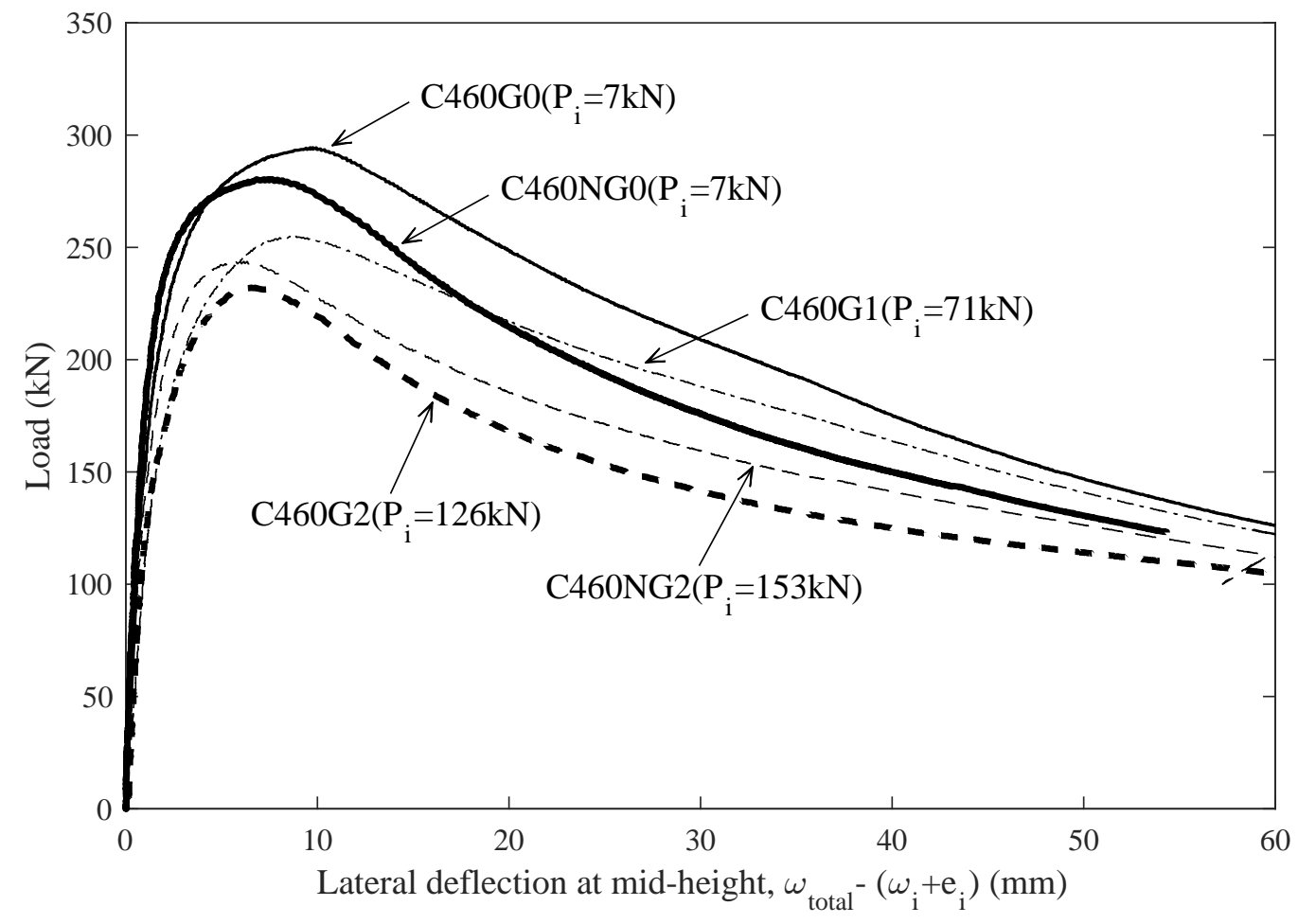

Figure 18: Load versus lateral deflection curves for the S460 compressive specimens.

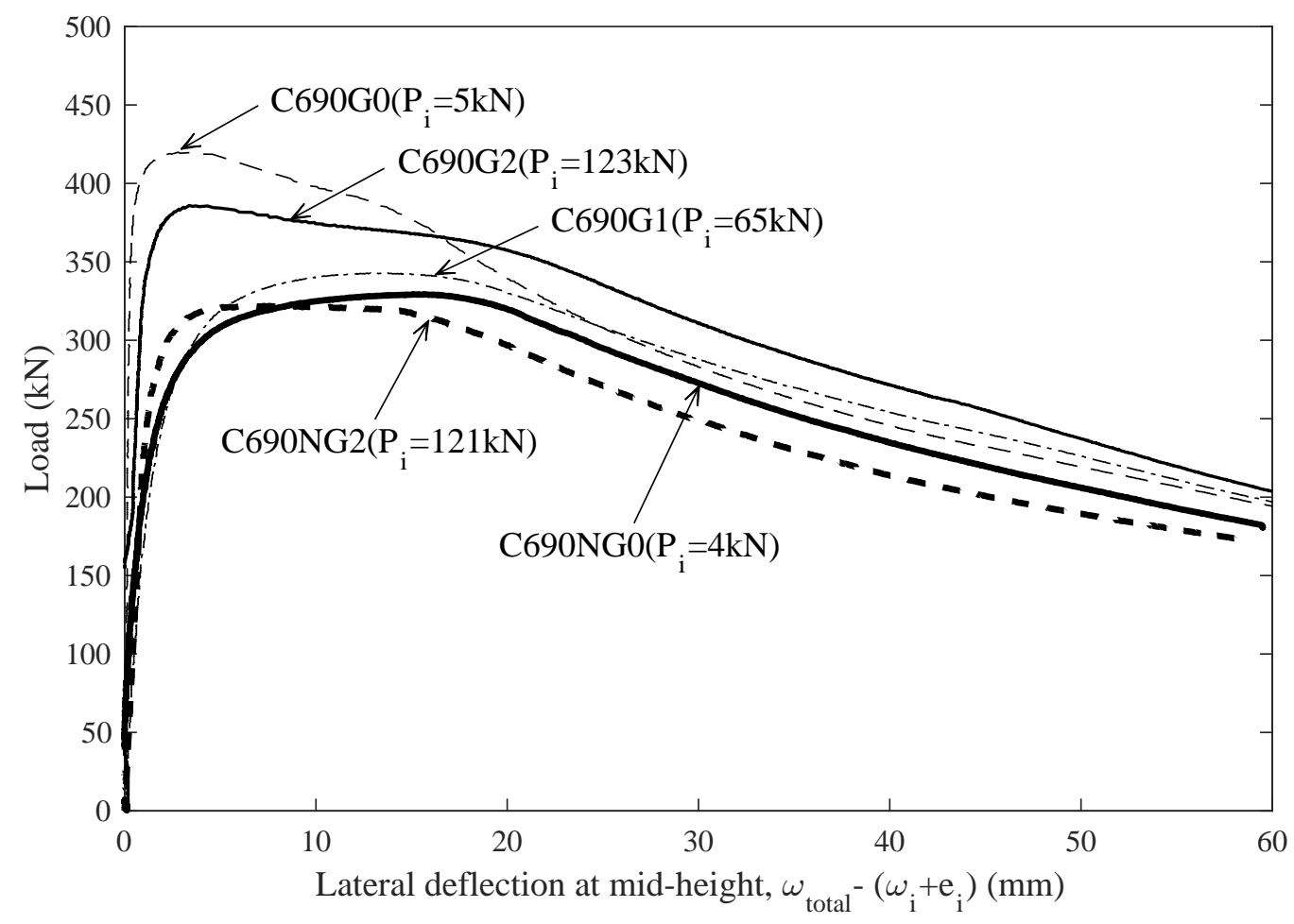

Figure 19: Load versus lateral deflection curves for the S690 compressive specimens. 


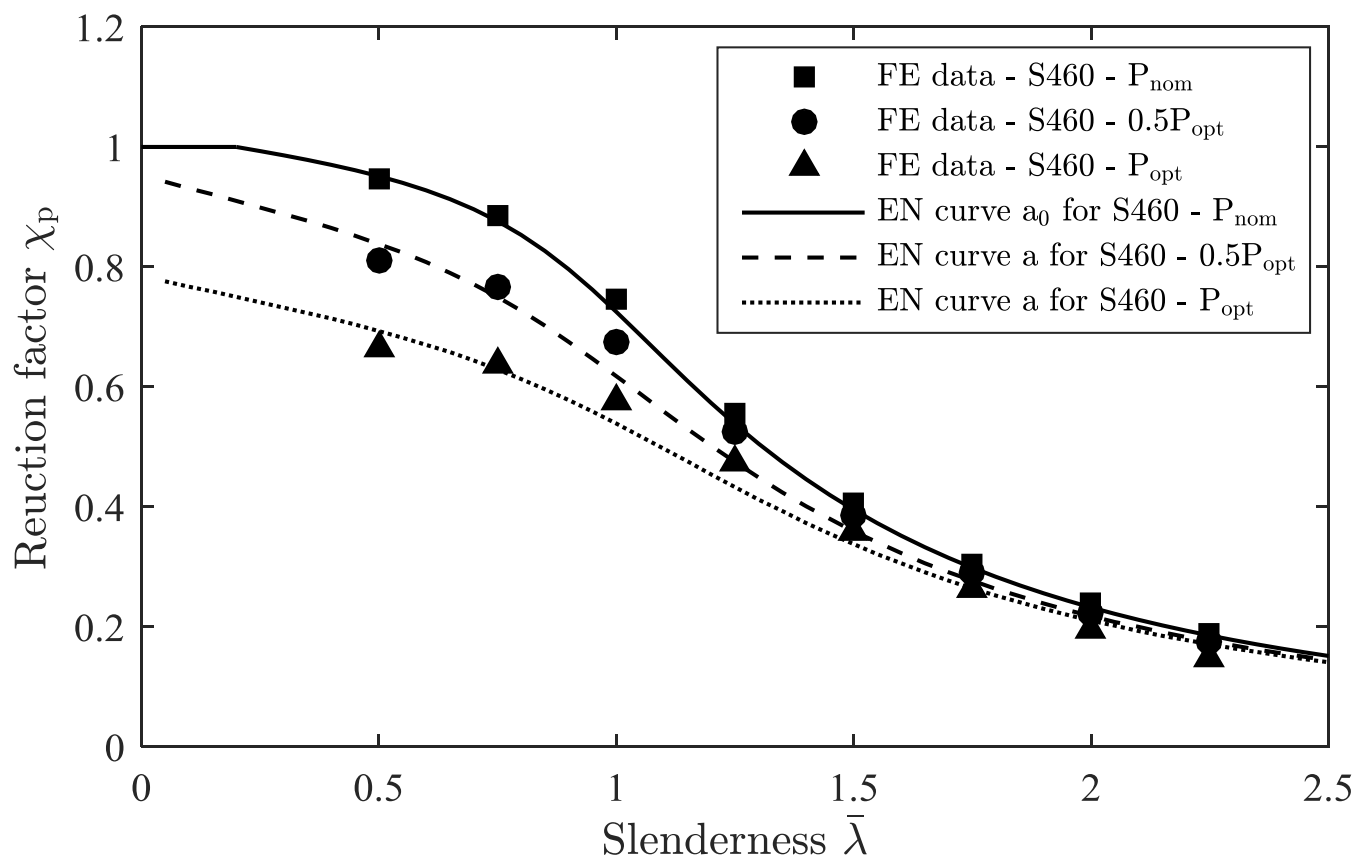

(a) $\mathrm{C} 460 \mathrm{NG}\left(\mathrm{A}_{\mathrm{c}}=100 \mathrm{~mm}^{2}\right)$

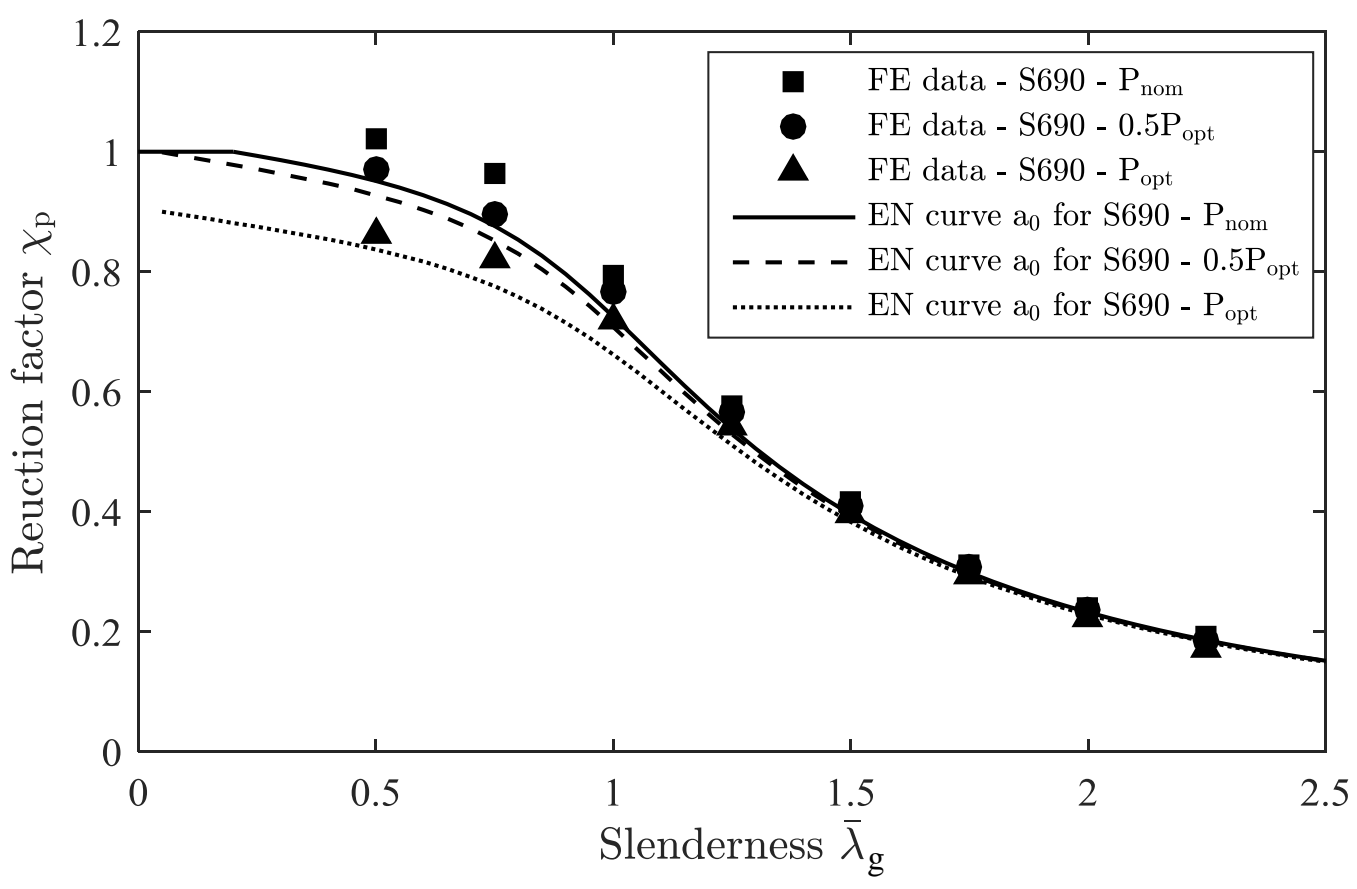

(b) C690G $\left(\mathrm{A}_{\mathrm{c}}=150 \mathrm{~mm}^{2}\right)$

Figure 20: Comparison between the modified EC 3 buckling curves and FE results. 